\title{
THEORETICAL AND EXPERIMENTAL ANALYSIS OF CONTACT RADIUS FOR SPHERICAL INDENTATION
}

\author{
Olivier Bartiera, Xavier Hernot ${ }^{\mathrm{b}}$, Gérard Mauvoisin ${ }^{\mathrm{c}}$ \\ ${ }^{a}$ L.A.R.M.A.U.R, E.A. 410, Bât 10B, Université de Rennes 1, Campus de Beaulieu, 35402 \\ Rennes Cedex, France. Olivier.bartier@univ-rennes1.fr \\ ${ }^{\text {b }}$ L.A.R.M.A.U.R, E.A. 410, Bât 10B, Université de Rennes 1, Campus de Beaulieu, 35402 \\ Rennes Cedex, France. Xavier.hernot@univ-rennes1.fr \\ ${ }^{c}$ L.A.R.M.A.U.R, E.A. 410, Bât 10B, Université de Rennes 1, Campus de Beaulieu, 35402 \\ Rennes Cedex, France. Gerard.mauvoisin@univ-rennes1.fr
}

Corresponding author : Olivier.bartier, Tel: +332 2323 6148; fax: +33223236111 E-mail address: Olivier.bartier@univ-rennes1.fr L.A.R.M.A.U.R, E.A. 410, Bât 10B, Université de Rennes 1, Campus de Beaulieu, 35402 Rennes Cedex, France.

\begin{abstract}
The study of analytical models for the determination of the contact radius between a spherical indenter and an elastic-plastic material is presented in this paper. Experimental results obtained for different spheroidized steels are compared to those obtained numerically and with various analytical models. The comparison between experimental and numerical indentation curves demonstrates that the indentation response of the studied steels can be correctly obtained starting from the work hardening behaviour determined by tensile test with the Bridgman method. The experimental and numerical comparison also shows that an increase in friction coefficient leads to a non negligible decrease in contact radius at large penetration depths. In consequence, an analytical model which is proposed with the assumption of friction contact allows a better contact radius to be determined. The comparison between the experimental and theoretical contact radius shows that the theoretical models, dependent only on the strain hardening exponent over-estimate the dimensionless contact radius, especially for low dimensionless contact radii, a/R. The models of Matthew (1980), Hill et al. (1989), Taljat et al. (1998) and Alcala et al. (2000) lead to acceptable results only for dimensionless contact radii, a/R, higher than 0.3 . Below this value, only the models of Lee et al. (2005), Hernot et al. (2006) and Kim et al. (2006) produce results that are close to those obtained experimentally. The present study shows that these last models enable an accurate assessment of contact area from measurements of penetration depth which is central to the analysis of instrumented indentation experiments.
\end{abstract}

\section{Keywords}

Spherical indentation, contact radius, penetration depth, Pile-up/sink-in, finite element method, experimental measurement

\section{Introduction}

During spherical indentation tests on elastic-plastic materials, the surface around the contact area can be deformed upwards or downwards along the $\mathrm{z}$ axis where load is applied. This behaviour is called piling-up, in the first case and sinking-in, in the second case. When the indented material is deformed elastically, sinking-in occurs. When the yield stress, $\sigma_{y}$, of the indented material is exceeded, the increase in plastic deformation of the indented material has 
a decrease in sinking-in and an increase in piling-up as a consequence. The presence of these phenomena has a negative effect on the determination of the projected area of contact. Consequently, this causes inaccuracies in the Young's modulus and hardness values provided by nano-indentation tests. This also makes difficult the determination of the stress-strain curves from indentation load-depth data. The study of the surface deformation around the imprint was presented in several papers (Norbury and Samuel, 1928; Matthews, 1980; Hill et al., 1989; Biwa and Störackers, 1995; Taljat et al., 1998; Mesarovic and Fleck, 1999; Alcala et al., 2000; Mata et al., 2002; Taljat and Pharr, 2004; Peralta et al., 2004; Lee et al., 2005; Hernot et al., 2006; Kim et al., 2006; Collin et al., 2008a). Some of these studies concern spherical indentation and led to relationships between the penetration depth, $\mathrm{h}$, the contact depth, $\mathrm{h}_{\mathrm{c}}$, and the contact radius, a, between the indenter and the indented material (Matthews, 1980; Hill et al., 1989; Taljat et al., 1998; Alcala et al., 2000; Kucharski and Mröz, 2001; Lee et al., 2005; Hernot et al., 2006; Kim et al., 2006; Collin et al., 2008a). The proposed models can be classified in several groups. Most of existing models, particularly the oldest, calculate the contact depth or the contact radius starting from the work hardening exponent of the indented material, n (Matthews, 1980; Hill et al., 1989; Taljat et al., 1998; Alcala et al., 2000; Kucharski and Mröz, 2001). These models were criticized recently by Hernot et al. (2006) because they do not take into account the influence of the penetration depth, the Young modulus, E, and the yield stress on the contact radius value. In order to take into account the influence of these parameters and of the work hardening exponent on the a-h relationship, two models were recently proposed by Lee et al. (2005) and Hernot et al. (2006). Another method was also proposed recently by Kim et al. (2006) in which the yield stress value is not necessary to determine the contact radius. A new formulation of the contact depth value depending on the value of the work hardening exponent, the maximum penetration depth and the elastic stiffness of the contact is given by Kim et al. (2006). A review of all these models shows that they are valid only for elastic-plastic materials for which the hardening behaviour follows the Hollomon hardening law $\left(\sigma=\sigma_{y}{ }^{(1-n)} E^{n} \varepsilon^{n}\right)$. Recently a methodology based on the Galin theory (1946) and the measure of the unloading stiffness was proposed by J.M. Collin et al. (2008a) in order to not take into account the type of work hardening of the indented material. This method allows the contact radius change during the indentation test to be determined even if the yield stress and the work hardening exponent are unknown. A thorough discussion of the various models presented previously is given in the appendix of this article.

The aim of this work is to compare the experimental results in the case of spherical indentation with those obtained thanks to various models proposed to determine the contact depth between a spherical indenter and an elastic-plastic material. To our knowledge, no study has been carried out on such comparison. For the study, different spheroidized steels, which are a very fine microstructure, were tested. The advantage of this type of microstructure is that there is no problem of structural heterogeneity during the indentation test carried out with a 1 $\mathrm{mm}$ or $2.5 \mathrm{~mm}$ diameter ball and loads ranging from $15 \mathrm{~N}$ to $200 \mathrm{~N}$. Another advantage of these materials is that, because of their resistance and the experimental conditions, the indentation results are obtained for elastic-plastic and fully plastic indentation regimes. In a first step, the stress-strain tensile curves of the tested steels are determined by using the Bridgman method in order to define the stress-strain relationship after necking (Bridgman, 1944). In order to verify that the indentation response of the spheroidized steels can be obtained correctly starting from the stress-strain tensile curves, numerical simulations of the spherical indentation test are carried out in the second step by using the Cast3M finite element code. Lastly, experimental spherical indentation tests were carried out using an experimental bench developed within our laboratory and the experimental results are compared with those obtained numerically and with those determined by using the models presented in this article. 


\section{Experimental parameters}

\subsection{Materials and thermal treatments}

The experimental tensile and indentation tests were carried out on the steels presented in Table 1 with the associated code for each material.

Table 1

As shown in Fig. 1, the selected samples are spheroidized steels. This type of steel was selected in order to obtain a fine and homogeneous microstructure and thus a good reproducibility of the indentation tests.

Figure 1

Fig. 1.c represents the microstructure of the AISI 1100 steel and shows an homogeneous distribution of spheroidized cementite particles in a ferritic matrix. The spheroidize annealing of this steel was carried out in an optimal way in order to obtain a soft and ductile material. This heat treatment was carried out prior to delivery of materials to our laboratory, which was not the case for the other steels. The ferritic-pearlitic structure AISI 1035, 1065 and 4135 steels were spheroidized within our laboratory with the parameters given in Table 1.

Figs. $1 \mathrm{~b}$ and $1 \mathrm{~d}$ show that some cementite lamellas are still present in the AISI 1065 and 4135 steels after heat treatment.

For the AISI 1035 steel, the ferritic grains and the old pearlitic grains in which the cementite lamellas were partially replaced by spheroidized particles can be distinguished in Fig. 1a.

For this steel, problems of reproducibility could occur during the indentation test if the imprint is located mainly in the ferritic grains or in the old pearlitic grains. Table 1, gives the Vickers hardness of the various tested materials and confirms that softening was not optimal for the AISI 1065 and 4135 steels. These steels are harder than the AISI 1100 steel because of partial spheroidizing. On the other hand, in spite of the small carbon percentage of the AISI 1035 steel, this one does not have hardness which is much lower than the AISI 4135 steel because of its partial spheroidized pearlite.

\subsection{Tensile tests}

The tensile tests are performed on a Lloyd LR system with a crosshead displacement rate of $2 \mathrm{~mm} / \mathrm{mn}$. The tensile curves are obtained starting from the standardized round bars presented in Fig. 2.

Figure 2

During tensile testing, the uniform extension ceases when the tensile load reaches a material specific maximum. At this point the test sample begins to neck. The state of stress changes gradually from the simple uniaxial tension to a complicated condition of triaxial stress for the round bar. Because the onset of necking destroys the uniaxial state of stress it is impossible to determine a uniaxial true stress-strain relationship by the standard tensile test once necking has occurred. Various methods have been proposed to obtain the true stress-strain relationship 
after necking (Bridgman, 1944; Davidenkov and Spriridonova, 1946; Dietrich et al., 1970; Gromada et al., 2004; Mirone, 2004). For rods, the Bridgman method (1944) is the most commonly used to obtain uniaxial true stress-strain relationships after necking. Contrary to the other methods, many numerical and experimental studies were performed on the Bridgman method (Gromada et al. 2004; Cabezas and Celentano, 2004; Celentano et al., 2004; Garcia-Garino et al., 2006). The results of these studies show that this technique is correct for taking into account the influence of the necking on the stress-strain relationship, especially when the radius of curvature of the surface in the neck region is much larger than the rod radius (Cabezas and Celentano, 2004; Celentano et al., 2004; Garcia-Garino et al., 2006). This explains why, in spite of its imperfection, the Bridgman method is used in order to determine the work hardening behaviour of a material after the onset of necking (Ling, 1996; Tillier, 1998; Cabezas and Celentano, 2004; Celentano et al., 2004; Garcia-Garino et al., 2006). In this study, the Bridgman method is used in order to define the post-necking behaviour of the spheroidized steels.

In the Bridgman method (1944), it is necessary to determine the applied load, the radius of the smallest cross section and the radius of curvature of the surface in the necking region. The radius of the smallest cross section and the radius of curvature of the surface were measured, at various steps of the tensile test, by using video frame grabbing. The evaluation of the necking profile curvature was carried out from the coordinates (in an arbitrary reference system) of at least 10 points per profile analysed. Then, the analytical expression of the obtained profile leads to the curvature value by way of fifth order polynomial fittings and their successive algebraic manipulation.

\subsection{Indentation tests}

\subsubsection{Finite element simulation}

Indentation simulations were performed, in axisymmetric mode, by using the Cast3M finite element code. The mesh used in this study was presented in a preceding article (Hernot et al., 2006). The simulations were carried out with spherical indenters of radius, $R$, equal to 0.5 and $1.25 \mathrm{~mm}$ and elastic properties corresponding to those of Tungsten carbide $(\mathrm{E}=600000 \mathrm{MPa}$ and $v=0.28)$.

The constitutive model of the indented material was taken to follow the well known $\mathrm{J}_{2^{-}}$ associated flow theory with rate-independent deformation and isotropic hardening. Yielding occurs according to the Von Mises criterion and the stress-strain relationship follows the piecewise linear/power-law:

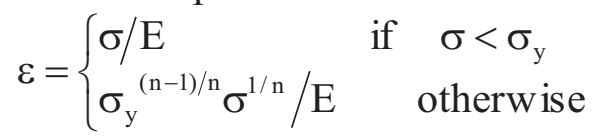

where $\varepsilon$ is the total strain, $\sigma$ is the stress, $\mathrm{E}$ is the Young modulus, $\sigma_{\mathrm{y}}$ is the yield stress and $\mathrm{n}$ is the strain hardening exponent. Young modulus of $210 \mathrm{GPa}$ and Poisson ratio of 0.3 are used for all simulations. Friction coefficients $\mu=0$ and $\mu=0.2$ were examined.

\subsubsection{Experimental bench for indentation test}

The experimental indentation tests were carried out by using an indentation instrumented bench designed and produced within our laboratory. A load cell measured load with a resolution of $0.02 \mathrm{~N}$ and the displacement was measured thanks to capacitive sensors which 
were fixed near the indenter. This gives the distance between the indenter and the indented surface of the tested material with a resolution of $0.02 \mu \mathrm{m}$.

The experimental system enables a maximum load equal to $200 \mathrm{~N}$ to be applied. For both tests carried out with spherical indenters of radius $\mathrm{R}=0.5 \mathrm{~mm}$ and $\mathrm{R}=1.25 \mathrm{~mm}$, the displacement rate was about $2 \mu \mathrm{m} / \mathrm{s}$.

\subsubsection{Determination of the load frame compliance of the experimental bench}

It is generally supposed that the total measured compliance, $\mathrm{C}_{\text {tot }}$, corresponds to the compliance of two springs in series:

$\mathrm{C}_{\text {tot }}=\mathrm{C}_{\text {sample }}+\mathrm{C}_{\mathrm{m}}$

Where $\mathrm{C}_{\text {sample }}$ is the sample compliance and $\mathrm{C}_{\mathrm{m}}$ is the load frame compliance. The total compliance is related to the total stiffness, $S_{\text {tot, }}$ by $C_{\text {tot }}=1 / S_{\text {tot }}$ and corresponds to the slope of the tangent line with relation to the experimental unloading curve at the maximum loading point. The sample compliance is related to the contact stiffness, $\mathrm{S}$, by $\mathrm{C}_{\text {sample }}=1 / \mathrm{S}$.

The measurable parameter being $S_{\text {tot }}$ and the material parameter required being $S$, it is thus essential to determine $C_{m}$ in order to calculate $S$. In other words, it is necessary to determine the load frame compliance of the experimental bench.

The contact stiffness, S, between a spherical indenter and a flat elastic half space can be obtained by the following relationship (Bulychev et al., 1975, 1976; Shorshorov et al., 1981):

$S=\frac{2}{\sqrt{\pi}} E^{*} \sqrt{A}$

where $\mathrm{A}$ is the projected contact area and $\mathrm{E}^{*}$ is the reduced modulus, calculated starting from the elastic properties of the sample, $E_{\text {mat }}$ and $v_{\text {mat }}$, and of the indenter, $E_{\text {ind }}$ and $v_{\text {ind }}$ such that:

$$
\mathrm{E}^{*}=\left(1 / \mathrm{E}_{\text {ind }}^{*}+1 / \mathrm{E}_{\text {mat }}^{*}\right)^{-1}=\left(\left(1-v_{\text {ind }}^{2}\right) / \mathrm{E}_{\text {ind }}+\left(1-v_{\text {mat }}{ }^{2}\right) / \mathrm{E}_{\text {mat }}\right)^{-1}
$$

Eqs. (2) and (3) show that the evolution of the total compliance versus the inverse of the square root of the contact area corresponds on a straight-line, $y=\alpha x+\beta$, where $y$ is the total compliance and $\mathrm{x}$ is the inverse of the square root of the contact area.

Starting from the $\mathrm{y}=\mathrm{C}_{\mathrm{m}}$ versus $x=1 / \sqrt{A}$ curve, the load frame compliance, $\mathrm{C}_{\mathrm{m}}=\beta$, and the reduced modulus, $\mathrm{E}^{*}=\alpha \sqrt{\pi} / 2$, can be obtained.

Table 2 recapitulates the values of the load frame compliance and the reduced modulus obtained for the tested materials and the two indenters used in this study.

\section{Table 2}

Table 2 shows that the experimental reduced modulii are close to the theoretical values obtained for the indented steel $(\mathrm{E}=210000 \mathrm{MPa}$ and $v=0.3)$ and a tungsten carbide indenter $(\mathrm{E}=600000 \mathrm{MPa}$ and $v=0.28$ ). The experimental results are smaller than the theoretical values, approximately $6 \%$ and $1 \%$ respectively for the $0.5 \mathrm{~mm}$ and $1.25 \mathrm{~mm}$ radius balls. 
In order to validate the value of the load frame compliance given in Table 2 for the carbide ball of radius equal to $0.5 \mathrm{~mm}$, numerical simulations were performed with the indenter represented in Fig. 3. Fig. 4 shows the results obtained for an indented steel of yield stress equal to $195 \mathrm{MPa}$ and hardening exponent equal to 0.233 (values corresponding to those of AISI 1100 steel). In this figure, the numerical load-displacement curves obtained at points $\mathrm{P}_{2}$ and $\mathrm{P}_{1}$ are shown (Fig. 3 ). These curves are compared to that calculated starting from the equation:

$$
\mathrm{h}\left(\mathrm{P}_{2}\right)=\mathrm{h}\left(\mathrm{P}_{1}\right)-\mathrm{C}_{\mathrm{m}} \mathrm{F}=\mathrm{h}\left(\mathrm{P}_{1}\right)-3.56 \mathrm{E}^{-6} \mathrm{~F}
$$

This figure shows that the load frame compliance given in Table 2 is correct to calculate the displacement of the point located on the top of the carbide ball $\left(\mathrm{P}_{2}\right.$, see Fig. 3) starting from the measurement of the displacement of the point located near the displacement sensors $\left(\mathrm{P}_{1}\right.$, Fig. 3).

\section{Figure 3}

\section{Figure 4}

Indeed, the theoretical and numerical displacements of the top of the carbide ball are very close. Fig. 5 confirms this result. In this figure, it is shown that the load frame compliance calculated experimentally $(3.56 \mathrm{E}-6 \mathrm{~mm} / \mathrm{N})$ is very close to that obtained numerically $(3.22 \mathrm{E}-6$ $\mathrm{mm} / \mathrm{N})$.

Figure 5

\section{Tensile tests}

The engineering tensile curves obtained for the studied materials are represented in Fig. 6.

Figure 6

In this figure, the reduction in the stress observed at various points of the engineering tensile curves corresponds to the stress relaxation of the steel during the frame grabbing carried out to take into account the necking effect. Table 3 summarizes the values of the yield stress, tensile stress and elongation at break of the studied steels.

\section{Table 3}

Fig. 6 and Table 3 show that the yield and tensile stresses are not related to the carbon percentage of the studied steels. As in the case of the hardness results, the absence of connection between strength and carbon percentage is due to the microstructure and in particular to the size and the shape of the cementite particles and also to the presence of pearlite lamellas because of the non optimal spheroidizing treatment of the AISI 1035, 1065 and 4135 steels (Fig. 1).

The true stress-strain curves obtained after applying the Bridgman method (1944) for the postnecking behaviour are represented Fig. 7 .

\section{Figure 7}


The main objective of the present study is to compare the results of the experimental indentation tests to those obtained with the theoretical models proposed to determine the contact depth between a spherical indenter and an elastic-plastic material (Matthews, 1980; Hill et al., 1989; Taljat et al., 1998; Alcala et al., 2000; Kucharski and Mröz, 2001; Lee et al., 2005; Hernot et al., 2006; Kim et al., 2006; Collin et al., 2008a). The theoretical models were proposed in the case of elastic-plastic materials for which the hardening behaviour follows the Hollomon hardening law (Eq. (1)).

Fig. 8 compares the experimental true stress-strain curves with those corresponding to the fitting of these curves by the Hollomon law. Different fits are performed, a first fit is performed up to the onset of necking, a second and a third, up to strains equal to 0.3 and 0.4 respectively and a fourth, until the break point.

\section{Figure 8}

As shown in Fig. 8, because of the low number of mechanical parameters in the Hollomon law, this law does not exactly fit the tensile curves, in the whole plastic range. In this figure, the curves can be fitted by two piecewise functions. Indeed, up to strain values of about 0.3 , the curve can be represented by a power law (Hollomon, Rambert-Osgood...). Fig. 8 shows that the Hollomon equation fits the tensile curve for strain values lower than about 0.3-0.4 very well, especially for AISI 1065 and 1100 steels. For higher strain values, the evolution of the stress-strain relationship is about linear. The values of the parameters of the Hollomon law obtained by fitting the stress-strain curve up to a strain of 0.3 are given in Table 3 .

\section{Indentation test}

\subsection{Load-displacement curves}

Indentation tests were performed under various maximum loads $25,50,75,100,150$, and 200 $\mathrm{N}$, with spherical indenters of diameter $\mathrm{D}=1 \mathrm{~mm}$ and $\mathrm{D}=2.5 \mathrm{~mm}$. In order to compare the results obtained with the two spherical indenters, the dimensionless parameters $\mathrm{h} / \mathrm{D}$ and $\mathrm{F}$ $\left(\mathrm{E}^{*}{ }_{\mathrm{mat}} \mathrm{D}^{2}\right)$ were used. Fig. 9 represents the experimental and numerical dimensionless loaddisplacement curves obtained with the two spherical indenters.

\section{figure 9}

Fig. 9 shows that a good reproducibility of the experimental results is obtained for the studied steels because the loading curves are superimposed for the various loads. Differences in results were however obtained for the AISI 1035 steel. The lack of reproducibility observed in the indentation curves can be due to the structural heterogeneity of the tested material. For the tested AISI 1035 steel, the spheroidized particles are only present in the old pearlitic grains (before spheroidized annealing). An indentation test performed in the ferritic grain or in the spheroidal pearlite can lead to different indentation curves.

In a general way, Fig. 9 shows that the numerical loading curves are close to the experimental loading curves. For the AISI 1065 and 1100 steels, the experimental loading curves are almost similar to those obtained numerically. For the AISI 1035 and 4135 steels, the numerical penetration depth is smaller than the experimental penetration depth. This difference between numerical and experimental curves can be caused by a difference between the true behaviour law of the material and that used for the numerical simulations. 
While the FEA curves agree quite well with the experimental results during the loading portion, there are some discrepancies in the unloading cycle. The experimental unloading curves exhibit greater curvature than the numerical unloading curves. Some of these differences could be attributed to the behaviour law of the different pieces deformed during the experimental indentation test. It is possible that the indentation stage and frame do not perform exactly as ideal Hookean springs, but rather exhibit some non-ideal elastic or even viscoelastic behaviour. In recent studies (Huber and Tsakmakis, 1998; Strange and Varsneya, 2001; Pane and Blank, 2006; Collin et al., 2008a, 2008b; Bartier et al., 2008), it has already been observed that the curvature of the experimental unloading curve was higher than the numerical one. In some of those studies (Huber and Tsakmakis, 1998; Strange and Varsneya, 2001; Pane and Blank, 2006; Bartier et al., 2008), numerical simulations show that isotropic or kinematic hardening has a considerable influence on the unloading curve. The unloading curves exhibit a higher curvature in the case of a kinematic hardening especially on the final part of these curves (Huber and Tsakmakis, 1998; Strange and Varsneya, 2001; Pane and Blank, 2006; Bartier et al., 2008). The analysis of the morphology of the imprints confirms this result (Huber and Tsakmakis, 1998; Strange and Varsneya, 2001; Pane and Blank, 2006; Bartier et al., 2008). In any case, the similarity of the experimental and numerical loading curves shows that the constitutive model used for the numerical simulations and the work hardening law determined by tensile test give the indentation behaviour of the studied steels with accurate results.

\subsection{Comparison between experimental and numerical values for contact radius and he/h ratio}

\subsubsection{Maximum plastic strain during the indentation tests}

The theoretical models for determining contact radius and $h_{c} / h$ ratio are valid in the case of elastic-plastic materials for which the hardening behaviour follows the Hollomon hardening law (Matthews, 1980; Hill et al., 1989; Taljat et al., 1998; Alcala et al., 2000; Kucharski and Mröz, 2001; Lee et al., 2005; Hernot et al., 2006; Kim et al., 2006; Collin et al., 2008a). The results of the tensile tests showed that the Hollomon equation fits the tensile curve of the studied steels for strain values lower than about 0.3-0.4 with good correlation. For strain values higher than about 0.3-0.4, the Hollomon law cannot be used in order to represent the tensile behaviour of the studied steels. In order to know if the Hollomon law can be used in the comparison between the results of the theoretical models with those obtained experimentally, it is thus necessary to study the values of the maximum plastic strain obtained in the indented zone during the indentation test.

With the aim of determining the values of the plastic strain in the indented steels, finite elements simulations were carried out by using the code Cast $3 \mathrm{M}$. The maximum plastic strain values in the indented zone are examined for an applied load of $200 \mathrm{~N}$ (maximum load for our experimental bench), and a spherical indenter of radius $\mathrm{R}=0.5 \mathrm{~mm}$ (smaller indenter radius). Fig. 10 shows the plastic strain isovalues obtained in the indented zone of the studied steels. In this figure, the plastic strain is the equivalent strain corresponding to the Von Mises stress.

\section{Figure 10}

Fig. 10 shows that the maximum plastic strain in the indented zone does not exceed $30 \%$ for the AISI 1065, 1100 and 4135 steels, when the maximum indentation load is applied.

For the AISI 1035 steel, the maximum plastic strain slightly exceeds this value and reaches $35 \%$. For all tested steels, the plastic strain does not exceed $10 \%$ in most of the plastic 
volume. Only the zone located under the indenter contains high plastic strain. Consequently, the fitting of the tensile curves by the Hollomon law, up to a strain equal to 0.3, can be used in order to correctly represent the behaviour of the studied steel during the indentation test.

\subsubsection{Indenter tip displacement determination}

In order to use the theoretical models to determine contact radius and $\mathrm{h}_{\mathrm{c}} / \mathrm{h}$ ratio (Matthews, 1980; Hill et al., 1989; Taljat et al., 1998; Alcala et al., 2000; Kucharski and Mröz, 2001; Lee et al., 2005; Hernot et al., 2006; Kim et al., 2006; Collin et al., 2008a), it is necessary to determine the penetration depth, $h$, measured from the reference surface (= original material surface) at loaded state. In Fig. 9, the displacement of the F-h curves corresponds to the displacement of a material point located in the tungsten carbide indenter, far from the contact zone, compared to the surface of the indented material (point $\mathrm{P}_{2}$, Fig. 3). The indenter being deformable, this displacement does not correspond to the penetration depth of the indenter tip (point $\mathrm{P}_{3}$, see Fig. 3), h. In order to compare the experimental values with those obtained from the theoretical models, it is thus necessary to take into account the elasticity of the indenter.

The penetration depth of the indenter tip at maximum loaded state, $\mathrm{h}^{\mathrm{F}_{\max }}$, can be obtained with the following equation:

$\mathrm{h}^{\mathrm{F}_{\max }}=\mathrm{h}_{\mathrm{F} \text {-hcurve }}^{\mathrm{F}_{\max }}-\mathrm{u}_{\mathrm{z}}^{\mathrm{F}_{\max }}$

Where $\mathrm{h}_{\mathrm{F}-\mathrm{h} \text { curve }}^{\mathrm{F}_{\max }}$ is the maximum penetration depth of the indenter obtained starting from the F-h curves and $\mathrm{u}_{\mathrm{z}}^{\mathrm{F}_{\max }}$ is the elastic displacement of a material point of the indenter toward the contact surface at maximum loaded state.

During spherical indentation test on elastic materials, the elastic displacement of a material point of the indenter, located in the symmetry axis and far to the indenter tip, with respect to the contact surface, is given by (Hertz, 1882):

$\mathrm{u}_{\mathrm{z}}=\frac{3}{4} \frac{\left(1-\mathrm{v}_{\text {ind }}^{2}\right)}{\mathrm{E}_{\text {ind }}} \frac{\mathrm{F}}{\mathrm{a}}$

For elastic plastic indented materials, it can be seen that the initially elliptical shape pressure distribution found in the elastic state flattens considerably as the load is progressively increased and becomes rather rectangular in shape (Hardy et al., 1971; Sinclair et al. 1985; Biwa et Störackers, 1995).

For the case of uniform pressure, the normal elastic displacement measured with respect to the original specimen is, at the center of contact, given by (Johnson, 1985):

$\mathrm{u}_{\mathrm{z}}=\frac{2}{\pi} \frac{\left(1-\mathrm{v}_{\text {ind }}{ }^{2}\right)}{\mathrm{E}_{\text {ind }}} \frac{\mathrm{F}}{\mathrm{a}}$

Fig. 11 shows the difference in displacement between the point located on the top of the carbide ball (point $\mathrm{P}_{2}$, see Fig. 3) and that located on the indented tip (point $\mathrm{P}_{3}$, Fig. 3), obtained numerically by F.E.M for materials similar to the AISI 1035 and 1100 steels. The numerical results are compared in this figure to the normal elastic displacements calculated with eqs. (7) and (8). Fig. 11 shows that Eq. (8) leads to a better evaluation of the elastic displacement of a material point of the spherical indenter toward the contact surface, when an elastic-plastic material is indented by a sphere. The difference between the displacement calculated with Eq. (8) and that obtained numerically by F.E.M. is very small (equal to about $0.15 \mu \mathrm{m}$ at maximum loaded state for the AISI 1035 and 1100 steels). 
Figure 11

Fig. 12 gives a comparison between the numerical F-h curve obtained for a rigid indenter and that obtained by using Eqs. (6) and (8) for AISI 1035 and 1100 indented steels and a tungsten carbide indenter, for which $E=600000 \mathrm{MPa}$ and $v=0.28$. It is observed that the F-h curves obtained for rigid indenter are closed to that obtained by using Eqs. (6) and (8) for a tungsten carbide indenter.

\section{Figure 12}

In conclusion, the experimental depth, $\mathrm{h}$, measured from the reference surface (= original material surface) at loaded state will be calculated in this study starting from Eq. (8) proposed in the case of uniform pressure.

\subsubsection{Contact radius determination}

The imprint radius has been determined by optical microscopy for indentation tests under various maximum loads $(25,50,75,100,150$, and $200 \mathrm{~N})$. For each imprint, the value of the radius corresponds to the average of 12 measurements. The contact radius at maximum loaded state is supposed to be similar to the imprint radius measured after unloading. This assumption is correct if the radial displacement of the point located at the edge of the contact only varies very slightly during unloading indentation.

Fig. 13 represents the evolution of the radial displacement of the point located at the edge of the contact numerically calculated during unloading indentation, for the studied steels. The results show that the radial displacement during the total unloading indentation is lower than $0.4 \mu \mathrm{m}$. This value being very small compared to the value of the contact radius (less than $0.72 \%$ ), it can be supposed that the imprint radius is similar to the contact radius obtained when the maximum indentation load is applied, i.e., when $\mathrm{F}=25,50,75,100,150$, or $200 \mathrm{~N}$. The same result was found by Rodriguez and Garrido Maneiro (2007) for spherical indentation on various elastic-plastic materials.

Figure 13

\subsubsection{Determination of the evolution of contact radius or contact depth during spherical indentation}

The dimensionless contact radius, $\mathrm{a} / \mathrm{R}$, obtained experimentally with the spherical indenters of diameter 1 and $2.5 \mathrm{~mm}$ are compared with those calculated by the theoretical models. The results obtained at different penetration depths for the studied steels are presented Fig. 14.

Figure 14

Fig. 14 shows that the models, which depend only on the strain hardening exponent, overestimate the dimensionless contact radius (Matthews, 1980; Hill et al., 1989; Taljat et al., 1998; Alcala et al., 2000; Kucharski and Mröz, 2001). The Kucharski et al. model (Kucharski and Mröz, 2001) overestimates the value of the contact radius the most. This model was proposed for a rigid-plastic material indented by ball. The over-estimation of the contact radius by this model is due to the elasticity and the well-developed yield stress of the tested 
materials, not taken into account in the Kucharski et al. model. Indeed, various works show that the smaller the $\sigma_{y} / E$ ratio, the higher the contact radius is (Lee et al., 2005; Hernot et al., 2006).The Collin et al. methodology (Collin et al., 2008a), based on the calculation of the slope of the unloading curve and the use of the BASh equation (Bulychev et al., 1975, 1976; Shorshorov et al., 1981), undervalue the value of the contact radius. According to the authors, this method gives a good evaluation of the contact radius only for values of $\mathrm{a} / \mathrm{R}$ ratios lower than 0.25 , which is not always the case for the experiments carried out in this study. Fig. 14 confirms that the values of the contact radius obtained by the methodology suggested by Collin et al. (2008a) are closest to those obtained experimentally for the lowest values of penetration depth. Fig. 9 shows that the initial slopes of the numerical unloading curves are often slightly higher than those of the experimental unloading curves. The calculation of the slope of the unloading curve is necessary in the case of the Collin et al. model. Due to the fact that the lesser, the smaller the contact radius, the low value of the contact radius could be due to a too low experimental elastic stiffness. The disadvantage of the method of Collin et al.(2008a) is that it requires precise determination of the initial slope of the unloading curves, which is not easy in experiments. However, it is important to note that this method is the only method which can give an evaluation of the contact radius during indentation without the knowledge of the yield strain and the strain hardening exponent values.

In order to compare the proposed models for the determination of the contact radius with more accuracy, the relationship between the hc/h ratio and the penetration depth, $h / R$, is represented in Fig. 15. For clarity, the results from Kucharski and Mröz and Collin et al. models are not represented in this figure.

Figure 15

Fig. 15 shows that the experimental ratio hc/h increases with the penetration depth. This result is in agreement with the theory. Indeed, it was shown that an elastic plastic material deforms only elastically at small depths, and that in this case, the indentation profile corresponds to that of Hertzian contact with $\mathrm{hc} / \mathrm{h}=0.5$. As the load on the indenter is increased, the plastic zone grows and spreads upward, and the sink-in diminishes; i.e. hc/h increases.

The hc/h results can be influenced by material heterogeneity, calibration errors and accuracy of the displacement sensors. Dispersion in hc/h results is higher for the AISI 1035 steel, for which structural heterogeneity is observed. The lack in precision in experimental results, especially for the low values of $\mathrm{h}^{*}$, is mainly due to the precision of the penetration depths measured experimentally starting from the indentation curve. When the spherical indenter with radius of $1.25 \mathrm{~mm}$ is used, the values of the penetration depth are very low for weak applied load For these conditions, a low error in the penetration depth measurement has, as a consequence, a high error in the hc/ $h$ and $\mathrm{a} / \mathrm{R}$ values.

The experimental results in Fig. 15 show that piling-up predominates when the hardening exponent of the indented material is weakest; i.e. AISI 1035 and AISI 4135 steels (Table 3). This result is in agreement with those obtained in previous experimental and numerical studies of metals indented by a ball (Norbury and Samuel, 1928; Matthews, 1980; Hill et al., 1989; Biwa and Störackers, 1995; Taljat et al., 1998; Alcala et al., 2000; Mata et al., 2002; Taljat and Pharr, 2004; Lee et al., 2005; Hernot et al., 2006). Fig. 15 confirms that the models, depending only on the strain hardening exponent, tends to over-estimate the dimensionless contact radius a/R (Matthews, 1980; Hill et al., 1989; Taljat et al., 1998; Alcala et al., 2000; Kucharski and Mröz, 2001). As mentioned in the annexe, the Matthew (1980), Hill et al. (1989), Taljat et al. (1998) and Alcala et al. (2000) models give acceptable results only for a dimensionless contact radius, $\mathrm{a} / \mathrm{R}$, higher than 0.3 and when $\sigma_{\mathrm{y}} / \mathrm{E}$ is smaller than about $1 / 330$ (Hernot et al., 2006). Fig. 15 confirms that the experimental results are closest to those 
obtained with these models when $\mathrm{a} / \mathrm{R}$ is higher than 0.3 . This figure also shows that the experimental results are closest to those obtained with these models for the steels with the lowest yield stress. When $\mathrm{a} / \mathrm{R}$ is lower than 0.3 , only the models proposed by Lee et al. (2005), Hernot et al. (2006) and Kim et al. (2006) lead to results close to the experimental ones. The comparison between the experimental results and the results of these models shows that the Lee et al. model overestimates the contact depth. The results obtained by the Hernot et al. model are very similar to the experimental ones when $h / R$ is lower than 0.02 . When $h / R$ is higher than 0.02 , the Hernot et al. model gives values of $\mathrm{hc} / \mathrm{h}$ higher than those obtained in the experiments as a whole. The overestimation of the contact depth by the Hernot et al. model can be due partly to the friction coefficient between the indenter and the indented steel. The Hernot et al. model was established starting from numerical calculations carried out with the assumption of frictionless contact. Finite elements calculations show however that an increase in friction coefficient has a decrease in hc/h ratio for large values of penetration depth, as a consequence (Mata et al., 2002; Taljat and Pharr, 2004; Hernot et al., 2006). Indeed, Fig. 15 shows that the numerical results are closer to those obtained in experiments when the friction coefficient is equal to 0.2. The Kim et al. model was obtained starting from results of finite element simulations carried out with a friction coefficient, between the ball and the indented material, equal to 0.2. The results obtained with this model are the closest to those obtained experimentally for large contact radius. As mentioned in the appendix, the definition of the contact depth given by Kim et al. (2006) is open to criticism. Moreover, the disadvantage of this model is that it requires precise determination of the initial slope of the unloading curve in order to obtain the elastic stiffness. In conclusion, despite their imperfections, the recent Lee et al., Hernot et al. and Kim et al. models allow a correct contact radius-penetration depth relationship to be determined.

\section{Conclusion}

The aim of this work was to study the analytical models for the determination of contact radius between a spherical indenter and an elastic-plastic material. In order to compare the results of these models with those obtained experimentally, tensile and indentation tests were performed on different spheroidized steels. The true stress-true strain curves of the tested steels are determined by using the Bridgman method in order to define the stress-strain relationship after necking. The comparison between experimental and numerical indentation curves demonstrates that the indentation response of the studied steels can be correctly obtained starting from the work hardening behaviour determined by tensile test with the Bridgman method. Finite element simulations show that for a maximum load of $200 \mathrm{~N}$, the maximum plastic strain in the indented zone does not exceed $30 \%$ for the studied steels. The experimental and numerical comparison also shows that an increase in friction coefficient leads to a non negligible decrease in contact radius for large penetration depth. Consequently, analytical models proposed with the assumption of friction contact allow a more accurate contact radius to be determined. The comparison between the experimental and theoretical contact radius shows that the theoretical models, depending only on the strain hardening exponent, over-estimate the dimensionless contact radius, especially for low dimensionless contact radii, a/R. The Matthew, Hill et al., Taljat et al. and Alcala et al. models lead to acceptable results only for dimensionless contact radii, $\mathrm{a} / \mathrm{R}$, higher than 0.3 . Below this value, only the Lee et al., Hernot et al. and Kim et al. models provide results which are close to the experimental ones. 


\section{Annexe : depth-contact radius relationship models for spherical indentation}

It is recognized that the material around the contact area can be deformed upwards or downwards along the $\mathrm{z}$ axis, during an indentation test. This behaviour is called piling-up in the first case and sinking-in in the second case. Fig. A.1 shows this phenomenon in both cases.

Figure A.1

When sinking-in occurs, the contact depth, $h_{c}$, is lower than the penetration depth, $h$, i.e; $h_{c} / h$ $<1$. In the case of piling-up, the $h_{c} / h$ ratio is higher than 1 .

\section{Elastic indentation regime}

In the case of material which is elastically deformed by indentation, $h_{c} / h$ is constant and equal to 0.5 (Sneddon, 1965).

\section{Elastic-plastic and plastic indentation regimes}

Norbury and Samuel (1928) were among the first to show that the profile of the surface indended by a sphere is characterized by piling-up or sinking-in depending on the hardening properties of the material. The level of contact perimeters, experimentally determined by these authors after unloading, shows that annealed metals, which are fully capable of hardening, exhibit sinking-in. On the contrary, cold-worked metals showing almost perfectly plastic behaviour are characterized by piling-up.

Moreover, they noticed a relationship between the ratio of $\left(h_{c}-h\right) / h$ and $(n+2)$, where $h_{c}$ is the contact depth (Fig. A.1) and (n+2) the exponent of the Meyer law (Meyer, 1908) given by :

$\mathrm{F}=\mathrm{ka}^{\mathrm{n}+2}$

in which, $\mathrm{F}$ is the applied load, $\mathrm{a}$ is the contact radius and $\mathrm{k}$ and $\mathrm{n}$ are material constants

According to this rule, Matthews (1980) proposed the following equation as a fit the Norbury and Samuel $h_{c} / h$ versus $n$ data obtained after unloading and loading, at a depth for which $a / R$ was mostly between 0.4 and 0.8 :

$$
\frac{\mathrm{h}_{\mathrm{c}}}{\mathrm{h}}=\frac{1}{2}\left(1+\frac{\mathrm{n}}{2}\right)^{2\left(\frac{1-\mathrm{n}}{\mathrm{n}}\right)}
$$

If the shape of the sphere can be approximated by a parabolic curve or for small displacements of the spherical indenter $\left(\mathrm{h}_{\mathrm{c}}<<\mathrm{R}\right)$, Eq. (A.2) can be expressed by using the $\mathrm{c}^{2}$ parameter introduced by Hill et al. (1989) as follows:

$\frac{\mathrm{h}_{\mathrm{c}}}{\mathrm{h}}=\frac{1}{2}\left(1+\frac{\mathrm{n}}{2}\right)^{2\left(\frac{1-\mathrm{n}}{\mathrm{n}}\right)} \approx \mathrm{c}^{2}=\frac{\mathrm{a}^{2}}{2 \mathrm{hR}}$

By using these equations, we can observe that, piling-up occurs, i.e $h_{c} / h$ and $c^{2}$ are higher than 1 , when $\mathrm{n}$ is smaller than approximately 0.262 .

More recently, Hill et al. (1989) conducted a theoretical and numerical study of the spherical indentation test using a nonlinear elastic constitutive model for the indented material. 
According to the authors, this model, equivalent to a rigid/plastic behaviour law for the Brinell test, should be applicable for elastic-plastic material, as for metals, over most of the plastic domain once the Meyer regime is established. The results of the theoretical study of the spherical indentation test show that the speculative formulae of Matthews (1980) is incompatible with the pressure distribution. From the results of this theoretical study and FE computations, Hill et al. (1989) proposed a new relationship for $\mathrm{c}^{2}$ depending on $\mathrm{n}$ valid for the loaded state, namely:

$\frac{\mathrm{h}_{\mathrm{c}}}{\mathrm{h}} \approx \mathrm{c}^{2}=\frac{5}{2}\left(\frac{2-\mathrm{n}}{4+\mathrm{n}}\right)$

It is important to notice that in this equation, the invariant $c^{2}$ only depends on $\mathrm{n}$ and cannot be influenced by the yield stress $\sigma_{\mathrm{y}}$ and the Young modulus $\mathrm{E}$ of the indented material and the friction coefficient $\mu$ between the indenter and the indented material because of the model used by the authors.

For a rigid-plastic material indented by ball, Kucharski and Mroz (2001) propose to replace the Hill formulation (A.4) by the following equation:

$\frac{\mathrm{h}_{\mathrm{c}}}{\mathrm{h}} \approx \mathrm{c}^{2}=1,4 \exp ^{(-0,97 \mathrm{n})}$

The comparison between results obtained starting from Eqs. (A.4) and (A.5) shows that the Kucharski and Mroz formulation gives higher values of hc/h than those obtained by the Hill et al. formulation.

Another formulation of $\mathrm{c}^{2}$, valid for materials of elastic-plastic constitutive behaviour, was proposed by Taljat et al. (1998) using the results of finite element simulations. For numerical simulations, the plastic constitutive behaviour was taken to follow $\mathrm{J}_{2}$-associated flow theory with rate-independent deformation and isotropic hardening. The plastic strain-hardening was represented by a power law curve similar to that given in Eq. (1) and Von Mises yield criterion was assumed. The $c^{2}$ formulation, determined using computed FE data obtained for an $\sigma_{\mathrm{y}} / \mathrm{E}=1 / 500$ material, a friction coefficient equal to 0.2 and an $\mathrm{a} / \mathrm{R}$ ratio equal to 0.5 , (1998) is:

$\frac{\mathrm{h}_{\mathrm{c}}}{\mathrm{h}} \approx \mathrm{c}^{2}=\frac{1}{4}\left(5-3 \mathrm{n}^{0.7}\right)$

As for the formulation proposed by Hill et al (1989), the invariant $\mathrm{c}^{2}$ of Eq. (A.6) cannot be influenced by $\sigma_{\mathrm{y}}, \mathrm{E}$ and $\mu$ because of the assumptions of the model used by Taljat et al. (1998).

The Norbury and Samuel data (1928) were also used by Alcala et al. (2000) in order to propose another $\mathrm{c}^{2}$ formulation. These data and experimental results, obtained for metals with $\sigma_{\mathrm{y}} / \mathrm{E}$ ranging between $1 / 1026$ and $1 / 296$, led to the following equation:

$\frac{\mathrm{h}_{\mathrm{c}}}{\mathrm{h}} \approx \mathrm{c}^{2}=1.276-1.748 \mathrm{n}+2.45 \ln ^{2}-1.469 \mathrm{n}^{3}$

It can be seen that as for the other formulations, $\mathrm{c}^{2}$ depends only on $\mathrm{n}$ in this last equation. It should be specified that Eq. A.7 is obtained by fitting experimental data. Consequently, this equation does not perfectly represent the evolution of $\mathrm{c}^{2}$ according to $\mathrm{n}$. Moreover, the small 
range of $\sigma_{\mathrm{y}} / \mathrm{E}$ values of the metals tested by Alcala et al. (2000), does not allow us to show if $\mathrm{E}$ or $\sigma_{\mathrm{y}}$ has an influence on $\mathrm{c}^{2}$.

The influence of $E$ or $\sigma_{y}$ on $h_{c} / h$ was shown by Hernot et al. (2006) thanks to finite element simulations of the spherical indentation of elastic-plastic materials for which the $\sigma_{\mathrm{y}} / \mathrm{E}$ ratio is in the range of $1 / 4200$ to $1 / 33$. The results show that the higher the value of $\sigma_{y} / E$ ratio, the larger the sinking-in is developed. The same behaviour was found for conical indentation by Mata et al. (2002) for materials with $\sigma_{\mathrm{y}} / \mathrm{E}$ ratio between $1 / 4000$ and $1 / 70$. Hernot et al. (2006) also found that, because of the assumptions of the different authors (Matthews, 1980; Hill et al., 1989; Taljat et al., 1998; Alcala et al., 2000), the analytical formulations, depending only on the hardening exponent (Eqs. (A.3), (A.4), (A.6), (A.7)), lead to acceptable results only for dimensionless contact radii, $\mathrm{a} / \mathrm{R}$, higher than 0.3 and when $\sigma_{\mathrm{y}} / \mathrm{E}$ is smaller than about $1 / 333$.

In order to take into account the influence of penetration depth, Young modulus, yield stress and the work hardening exponent on the $h_{c} / h$ ratio, two models were recently proposed by Lee et al. (2005) and Hernot et al. (2006).

The Lee et al. model was proposed starting from numerical simulations of indentation by ball with a diameter $\mathrm{D}=1 \mathrm{~mm}$, a Young's modulus $\mathrm{E}=537 \mathrm{GPa}$ and a Poisson' s ratio $v=0.24$. The finite elements simulations were performed for materials with $\sigma_{\mathrm{y}} / \mathrm{E}$ ratio between $1 / 2000$ and $1 / 87.5$ and strain hardening exponent in the range of 0.02 to 0.999 . The Lee et al model is:

$$
\begin{aligned}
& \mathrm{c}^{2}=\frac{\mathrm{h}_{\mathrm{c}}}{\mathrm{h}}=\mathrm{f}_{0}^{\mathrm{c}}\left(\frac{\sigma_{\mathrm{y}}}{\mathrm{E}}, \mathrm{n}\right)+\mathrm{f}_{\mathrm{i}}^{\mathrm{c}}\left(\frac{\sigma_{\mathrm{y}}}{\mathrm{E}}, \mathrm{n}\right) \ln (\mathrm{h} / \mathrm{D}), \\
& \mathrm{f}_{\mathrm{i}}^{\mathrm{c}}\left(\frac{\sigma_{\mathrm{y}}}{\mathrm{E}}, \mathrm{n}\right)=\mathrm{a}_{\mathrm{ij}}\left(\frac{\sigma_{\mathrm{y}}}{\mathrm{E}}\right) \mathrm{n}^{-\mathrm{j}}, \quad \mathrm{i}=0,1, \quad \mathrm{j}=0,1,2,3,4, \\
& a_{i j}\left(\frac{\sigma_{y}}{E}\right)=\alpha_{i j k}\left(\frac{\sigma_{y}{ }^{k}}{E}\right), \quad k=0,1,2,3 .
\end{aligned}
$$

This model confirms that the smaller the $\sigma_{\mathrm{y}} / \mathrm{E}$ and the strain hardening exponent are, the earlier the pile up arises. This model also shows that the higher the value of penetration depth, the larger the piling-up is developed. The main disadvantage of the Lee et al model is its complexity because it requires the use of 40 coefficients $\alpha \mathrm{ijk}$ in order to determine the $\mathrm{hc} / \mathrm{h}$ ratio.

The Hernot et al. model was also proposed starting from numerical simulations results. Finite element simulations were performed for materials exhibiting all possible combinations of $\sigma_{\mathrm{y}}=$ $50,100,250,630,1600,2500,4000$ and $6300 \mathrm{MPa}$ and $\mathrm{n}=0,0.1,0.2,0.3$ and 0.4. Young modulus of $210 \mathrm{GPa}$ and Poisson ratio of 0.3 were used for all simulations. These values were chosen in order to give $\sigma_{\mathrm{y}} / \mathrm{E}$ ratio in the range of $1 / 4200-1 / 33$, which includes most of metals. The Hernot et al model is given by:

$$
\mathrm{c}^{2}=\frac{\mathrm{h}_{\mathrm{c}}}{\mathrm{h}}=\mathrm{M}\left[2\left(1-\sqrt{1-\left(\frac{\mathrm{a}}{\mathrm{R}}\right)^{2}}\right)\right]^{(2-\mathrm{N}) / 2}=\mathrm{M}^{2 / \mathrm{N}}\left(2 \frac{\mathrm{h}}{\mathrm{R}}\right)^{(2-\mathrm{N}) / \mathrm{N}}
$$

with: 


$$
\begin{aligned}
& \mathrm{M}=\frac{\left(1,45+28,55 \mathrm{n}+1745 \sigma_{\mathrm{y}}^{*}\right)\left(1-0,5 \mathrm{n}+20 \sigma_{\mathrm{y}}^{*}\right)}{\left(1+21,4 \mathrm{n}+1020 \sigma_{\mathrm{y}}^{*}\right)\left(1+0,4 \mathrm{n}+60 \sigma_{\mathrm{y}}^{*}\right)} \\
& \mathrm{N}=\frac{\left(1,9+12,5 \mathrm{n}+570 \sigma_{\mathrm{y}}^{*}\right)(1+0,1 \mathrm{n})}{\left(1+6,8 \mathrm{n}+340 \sigma_{\mathrm{y}}^{*}\right)}
\end{aligned}
$$

where $\sigma_{\mathrm{y}}{ }^{*}=\sigma_{\mathrm{y}} / \mathrm{E}$.

As the Lee et al. model, the Hernot et al model shows that the smaller the $\sigma_{\mathrm{y}} / \mathrm{E}$ and the higher the penetration depth are, the larger the hc/h ratio is. The advantage of the Hernot et al. model is that it is simpler than the Lee et al. model.

The Hernot et al. model has also the advantage of being established for a greater range of $\sigma_{\mathrm{y}} /$ E ratios, $\frac{1}{4200} \leq \frac{\sigma_{y}}{E} \leq \frac{1}{33}$ for the Hernot et al. model and $\frac{1}{2000} \leq \frac{\sigma_{\mathrm{y}}}{\mathrm{E}} \leq \frac{1}{88}$ for the Lee et al model. The Hernot et al. model is also valid for higher values of penetration depth. Indeed, the model of Lee et al. (2005) was proposed starting from finite elements simulations performed up to an $\mathrm{h} / \mathrm{R}$ ratio equal to 0.12 , which corresponds to a $\mathrm{a} / \mathrm{R}$ ratio equal to 0.49 . For the Hernot et al. model, the finite elements simulations were performed up to an $\mathrm{h} / \mathrm{R}$ ratio equal to 0.4 , which corresponds to an a/R ratio equal to 0.8 . On the other hand, the Hernot et al. model was established for materials of strain hardening exponent lower than 0.4 , which is not the case for the Lee et al. model.

A method different from those presented in the two preceding studies was also proposed recently by Kim et al. (2006) in order to take into account the influence of $\mathrm{E}, \sigma_{\mathrm{y}}$ and the penetration depth on the hc/h ratio, in the case of spherical indentation.

When the yield stress, $\sigma_{y}$, of the indented material is exceeded during spherical indentation, Kim et al. (2006) propose to allot the phenomenon "sinking-in, piling-up" to two independent behaviours. Sinking-in is caused by the elasticity of the indented material and piling-up is due to the plastic deformation. The contact depth, hc, is thus obtained by the addition of two independent terms:

$\mathrm{h}_{\mathrm{c}}=\mathrm{h}_{\mathrm{c}}^{*}+\mathrm{h}_{\text {pile }}^{*}$

Where $h_{c}^{*}$ is the elastic contact depth and $h_{\text {pile }}^{*}$ is the increase in depth from $h_{c}^{*}$ by the plastic pile-up phenomenon.

Starting from results of numerical simulations, Kim et al. (2006) show that the contact depth, due to the elastic deflection can be calculated by using Oliver and Pharr's method (Oliver and Pharr, 1992), starting from the unloading curve, i.e.:

$$
\mathrm{h}_{\mathrm{c}}^{*}=\mathrm{h}_{\max }-\varepsilon \frac{\mathrm{F}_{\max }}{\mathrm{S}}
$$

Where $\mathrm{h}_{\max }$ and $\mathrm{F}_{\max }$ are respectively the maximum depth and the maximum applied load, $\varepsilon$ is a constant related to the geometry of the indenter $(\varepsilon=0.75$ for a paraboloid of revolution) and $\mathrm{S}$ is the experimentally measured stiffness of the upper portion of the unloading data.

Thanks to the definition of the contact depth given by Eq. (A.10) and finite elements results, it is shown, that $\sigma_{\mathrm{y}} / \mathrm{E}$ does not have much influence on $\mathrm{h}_{\text {pile }}^{*}$. On the basis of this observation, Kim et al. (2006) propose the following formulation to determine the increase in depth from $\mathrm{h}_{\mathrm{c}}^{*}$ by the plastic pile-up phenomenon, i.e. $\mathrm{h}_{\text {pile }}^{*}$ : 


$$
\mathrm{h}_{\text {pile }}^{*}=0,131\left(1-3,423 \mathrm{n}+0,079 \mathrm{n}^{2}\right)\left(1+6,258 \frac{\mathrm{h}_{\max }}{\mathrm{R}}-8,072\left(\frac{\mathrm{h}_{\max }}{\mathrm{R}}\right)^{2}\right) \mathrm{h}_{\mathrm{c}}^{*}
$$

Where $\mathrm{R}$ is the indenter radius and $\mathrm{n}$ is the strain hardening exponent of the indented material. The disadvantage of this model is that it requires precise determination of the initial slope of the unloading curve in order to obtain the elastic stiffness, S. Moreover, this method is open to criticism due to the relevance of the definition of the contact depth given by Eq. (A.10) and especially because of the manner in which the contact depth was calculated. An examination of the Kim et al. results shows that the elastic contact depth calculated by using Eq. (A.11) is over-estimated compared to that obtained numerically, especially for materials of small $\sigma_{y} / \mathrm{E}$ ratio. In the same way, another examination of the Kim et al. results shows that the $\mathrm{h}_{\text {pile }}^{*}$ is little influenced by $\sigma_{y} / E$, but $h_{\text {pile }}^{*} / h_{c}^{*}$ increases when $\sigma_{y} / E$ decreases. This result indicates that the definition of the contact depth given by Eq. (A.10) does not make it possible to completely dissociate the pile-up/sink-in phenomenon into two independent behaviours, "elastic deflection" and "plastic pileup"

One disadvantage of the preceding models is that they are valid only for elastic-plastic materials for which the hardening behaviour follows the Hollomon hardening law $\left(\sigma=\sigma_{\mathrm{y}}{ }^{(1-n)}\right.$ $\left.\mathrm{E}^{\mathrm{n}} \varepsilon^{\mathrm{n}}\right)$.

The models proposed by Matthews (1980), Hill et al. (1989), Taljat et al. (1998), Alcala et al. (2000), Kucharski and Mroz (2001) and Kim et al. (2006) require knowledge of the strain hardening exponent and those proposed by Lee et al. (2005) and Hernot et al. (2006) require knowledge of both the strain hardening exponent and the yield stress.

In order to avoid the determination of the elastic-plastic behaviour law of material before determining hc/h, a methodology, based on the use of the BASh equation (Bulychev et al., 1975, 1976; Shorshorov et al., 1981), was recently proposed by J.M Collin et al. (2008a). Collin et al. (2008a) also suggest using the correction of the BASh equation proposed by Hay and Wolf (2001) in order to obtain a radial displacement compatible with the indenter geometry.

The combination of the BASh equation and this correction gives the following equations:

$$
\frac{\mathrm{h}_{\mathrm{c}}}{\mathrm{h}} \approx \mathrm{c}^{2}=\left[\frac{3 \pi(\sqrt{\Delta(\mathrm{h})}-1)}{4 \mathrm{~B}}\right]^{2} \frac{\mathrm{R}}{2 \mathrm{~h}}
$$

where

$$
\Delta(\mathrm{h})=1+\frac{4 \mathrm{BS}}{3 \pi \mathrm{RE}^{*}} \quad ; \quad \mathrm{B}=\left[\frac{\mathrm{N}\left(1-v_{\text {mat }}\right)\left(1+v_{\text {mat }}\right)}{\mathrm{N}\left(1-v_{\text {mat }}^{2}\right)+\left(1+v_{\text {ind }}{ }^{2}\right)}\right] \quad ; \quad \mathrm{N}=\frac{\mathrm{E}_{\text {ind }}}{\mathrm{E}_{\text {mat }}}
$$

This method requires knowledge of the elastic parameters of indented material and of the indenter which can be easily found in the literature or determined by a non destructive technique such as the ultrasonic method. It also necessitates the programming of several loading, unloading and reloading cycles in order to determine unloading stiffness changes $\mathrm{S}(\mathrm{h})$. According to Collin et al. (2008a), the best evaluation of contact radius is obtained when $\mathrm{a} / \mathrm{R}$ is lower than 0.25 because of the use of the BASh equation (Bulychev et al., 1975, 1976; Shorshorov et al., 1981) corrected by Hay and Wolf (2001). Finally, the method proposed by Collin et al. (2008a) does not necessitate the knowledge of the yield stress and the strain hardening exponent of the tested material. This is a real advantage when the indentation test is carried out on material in order to determine its characterisation. 


\section{References}

Alcala, J., Barone, A.C., Anglada, M., 2000. The influence of plastic hardening on surface deformation modes around Vickers and spherical indents. Acta Mater. 48, 3451-3464.

Bartier, O., Kucharski, S., Mauvoisin, G., 2008. Numerical and experimental studies of spherical indentation data : influence of the friction coefficient and the hardening behaviour Mat. Tech., special issue 96, 59-70.

Biwa S., Störackers B., 1995. An analysis of fully plastic Brinell indentation. J. Mech. Phys. Solids 8, 1303-1333.

Bridgman, P., 1944. The stress distribution at the neck of a tensile Specimen. Trans. Am. Soc. Met. 32, 553-574.

Bulychev, S.I.,, Alekhin, V.P.,, Shorshorov, M.K.,, Ternovskii, A.P., Shnyrev, G.D., 1975. Determining Young's modulus from the indentor penetration diagram. Zavod. Lab. 41, 1371140 .

Bulychev, S.I., Alekhin, V.P., Shorshorov, M.K., Ternovskii, A.P., Shnyrev, G.D., 1976. Mechanical properties of materials studied from kinetic diagrams of load versus depth of impression during microimpression. Strength Mater. 8, 1084-1089.

Cabezas, E. E., Celentano, D. J., 2004. Experimental and numerical analysis of the tensile test using sheet specimens. Finite Elem. Anal. Des. 40, 555-575.

Celentano, D. J., Cabezas, E. E., Garcia, C. M., Monsalve, A. E., 2004. Characterization of the mechanical behaviour of materials in the tensile test: experiments and Simulation. Modelling Simul. Mater. Sci. Eng. 12, 425-444.

Collin, J. M., Mauvoisin, G., El Abdi, R., 2008a. An experimental method to determine the contact radius changes during a spherical instrumented indentation. Mech. Mater. 40, 401406.

Collin, J. M., Mauvoisin, G., Pilvin, P., El Abdi, R., 2008b. Use of spherical indentation data changes to materials characterization based on a new multiple cyclic loading protocol Mater. Sci. Eng. A 488, 608-622.

Davidenkov, N., Spiridonova, N., 1946. Analysis of the state of stress in the neck of a tension test specimen. Proc. Am. Soc. Test. Mat. 46, 1147-1158.

Dietrich, L., Miastkowski, J., Szczepiński, W., 1970. Nośność graniczna elementów konstrukcji, PWN, Warszawa.

Galin, L.A., 1946. Spatial contact problems of the theory of elasticity for punches of circular shape in planar projection. J. Appl. Math. Mech. 10, 425-448.

García-Garino, C., Gabaldón, F., Goicolea, J. M., 2006. Finite element simulation of the simple tension test in metals. Finite Elem. Anal. Des. 42, 1187-1197.

Gromada, M., Mishuris, G., Öchsner, A., 2004. Critical analysis of the evaluation of plastic material properties obtained from standard round tensile specimens. Proc. of the $3^{\text {th }}$ International Conference on Mathematical Modeling and Computer Simulation of Materials Technology (MMT-2004), Ariel, Israel, 78-87.

Hardy, C., Baronet, C. N., Tordion, G. V., 1971. The elasto-plastic indentation of a half-space by a rigid sphere. Int. J. Numer. Methods Eng. 3, 451-462.

Hay, J.C., Wolff, P.J., 2001. Small correction required when applying the Hertzian contact model to instrumented indentation data. J. Mater. Res. 16, 1280-1286.

Hernot, X., Bartier, O., Bekouche, Y., Mauvoisin, G., El Abdi, R., 2006. Influence of penetration depth and mechanical properties on contact radius determination for spherical indentation. Int. J. Solids Struct. 43, 4136-4153.

Hertz, H., 1882. Uber die Berührung festischer Körper. J. Reine Angew. Math. 92, 156-171. 
Hill, R., Stôrakers, B., Zdunek, A.B., 1989. A theoretical study of the Brinell hardness test. R. Soc. Lond. A 423, 301-330.

Huber, N., Tsakmakis, Ch., 1998. Experimental and theoretical investigation of the effect of kinematic hardening on spherical indentation. Mech. Mat. 27, 241-248.

Johnson, K.L., 1985. Contact mechanics, Cambridge University Press, Cambridge, U. K.

Kim, S.H., Lee, B. W., Choi, Y., Kwon, D., 2006. Quantitative determination of contact depth during spherical indentation of metallic materials - A FEM study. Mater. Sci. Eng. A 415, 5965

Kucharski, S., Mröz, Z., 2001. Identification of plastic hardening parameters of metals from spherical indentation tests Mater. Sci. Eng. A 318, 65-76.

Lee, H., Lee, J. H., Pharr, G. M., 2005. A numerical approach to spherical indentation techniques for material property evaluation. J. Mech. Phys. Solids 53, 2037-2069.

Ling, Y., 1996. Uniaxial True Stress-Strain after Necking. AMP J. Technol. 5, 37-48.

Mata, M., Anglada, M., Alcala, J., 2002. Contact deformation regimes around sharp indentations and the concept of the characteristic strain. J. Mater. Res. 17, 964-976.

Matthews, J.R., 1980. Indentation hardness and hot pressing. Acta Metall. 28, 311-318.

Mesarovic, D. J., Fleck, N. A., 1999. Spherical indentation of elastic-plastic solids. Proc. R. Soc. Lond. A. 455, 2707-2728.

Meyer E., 1908. Untersuchen über Härteprüfung und Härte. Zeits. D. Vereines Deutsch. Ingenieure 52, pp. 645-654.

Mirone, G., 2004. A new model for the elastoplastic characterization and the stress-strain determination on the necking section of a tensile specimen. Int. J. Solids Struct. 41, 35453564 .

Norbury, A., Samuel, T., 1928. The recovery and sinking-in or piling-up of material in the Brinell test, and the effect of these factors on the correlation of the Brinell with certain other hardness tests. J. Iron Steel Inst. 117, 673-687.

Oliver, W.C., Pharr, G.M., 1992. An improved technique for determining hardness and elastic modulus using load and displacement sensing indentation experiments. J. Mater. Res. 7, 15641583.

Pane, I., Blank, E., 2006. Role of plasticity on indentation behavior: Relations between surface and subsurface responses. Int. J. Solids Struct. 43, 2014-2036.

Peralta, P., Ledoux, R., Dickerson, R., Hakik, M., Dickerson, P., 2004. Characterization of Surface Deformation around Vickers Indents in Monocrystalline Materials. Metall. Mater. Trans. A 35A, 2247-2255.

Rodriguez, J.; Garrido Maneiro M.A., 2007. A procedure to prevent pile up effects on the analysis of spherical indentation data in elastic-plastic materials. Mech. Mater. 39, 987997Shorshorov, M.K., Bulychev, S.I., Alekhin, V.P., 1981. Work of plastic and elastic deformation during indenter indentation. Sov. Phys. Dok1. 26, 769-771.

Sinclair, G. B., Follansbee, P. S., Johnson, K. L., 1985. Quasi-static normal indentation of an elasto-plastic half-space by a rigid sphere, ii. Results. Int. J. Solids Struct. 21, 865-888.

Sneddon, I.N., 1965. The relation between load and penetration in the axisymmetric

Boussinesq problem for a punch of arbitrary profile. Int. J. Eng. Sci. 3, 47-57.

Strange, D. J., Varshneya, A. K., 2001. Finite element simulation of microindentation on aluminium. J. Mat. Sci. 36 () 1943-1949.

Taljat, B., Pharr, G.M., 2004. Development of pile-up during spherical indentation of elasticplastic solids. Int. J. Solids Struct. 41, 3891-3904.

Taljat, B., Zacharias, T., Kosel, T, 1998. New analytical procedure to determine stress-strain curve from spherical indentation data. Int. J. Solids Struct. 35, 4411-4426. 
Tillier Y., 1998. Identification par analyse inverse du comportement mécanique des polymères solides; applications aux sollicitations multiaxiales et rapides, Doctor's Thesis, ENSAM PARIS. 


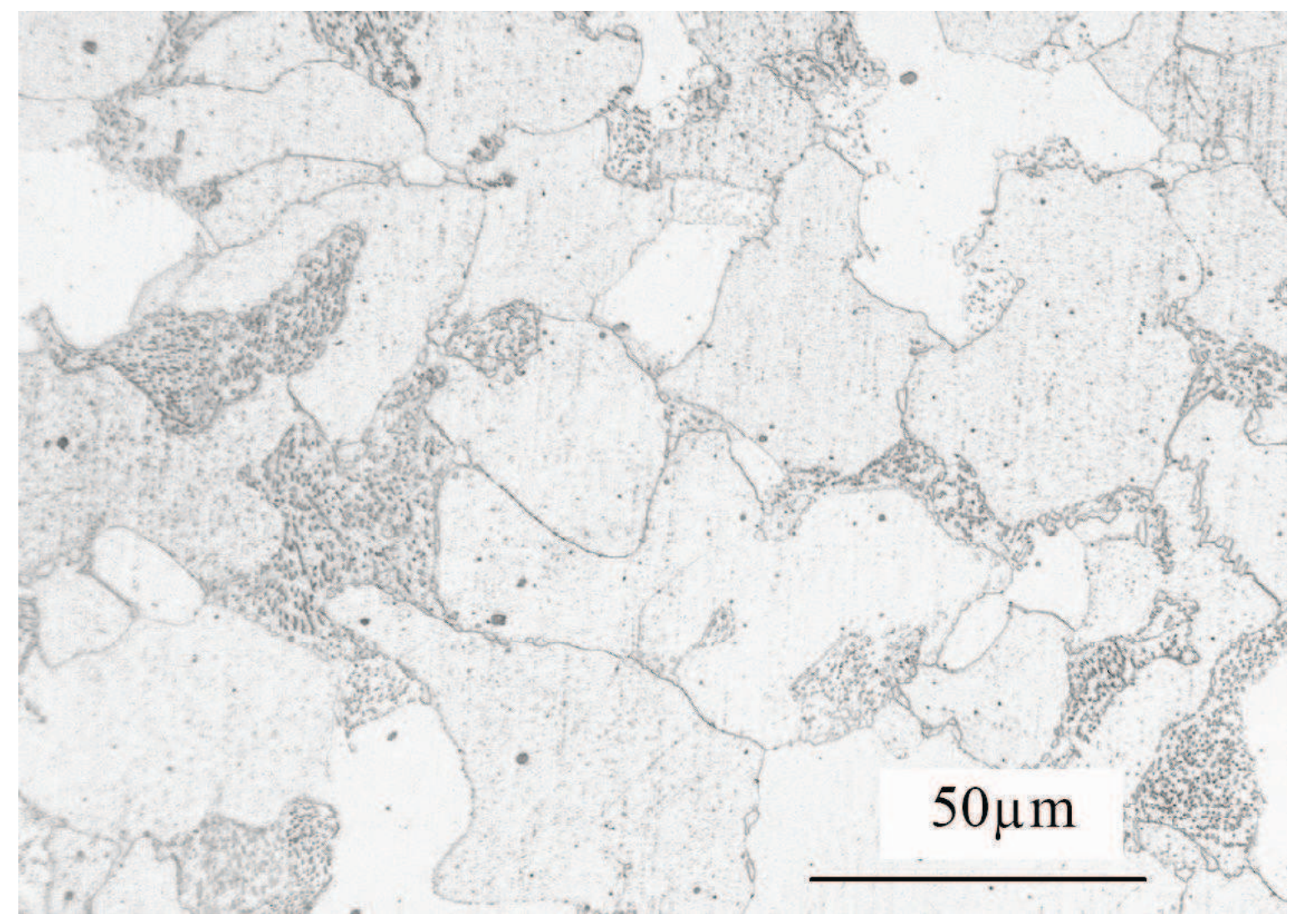

(a)

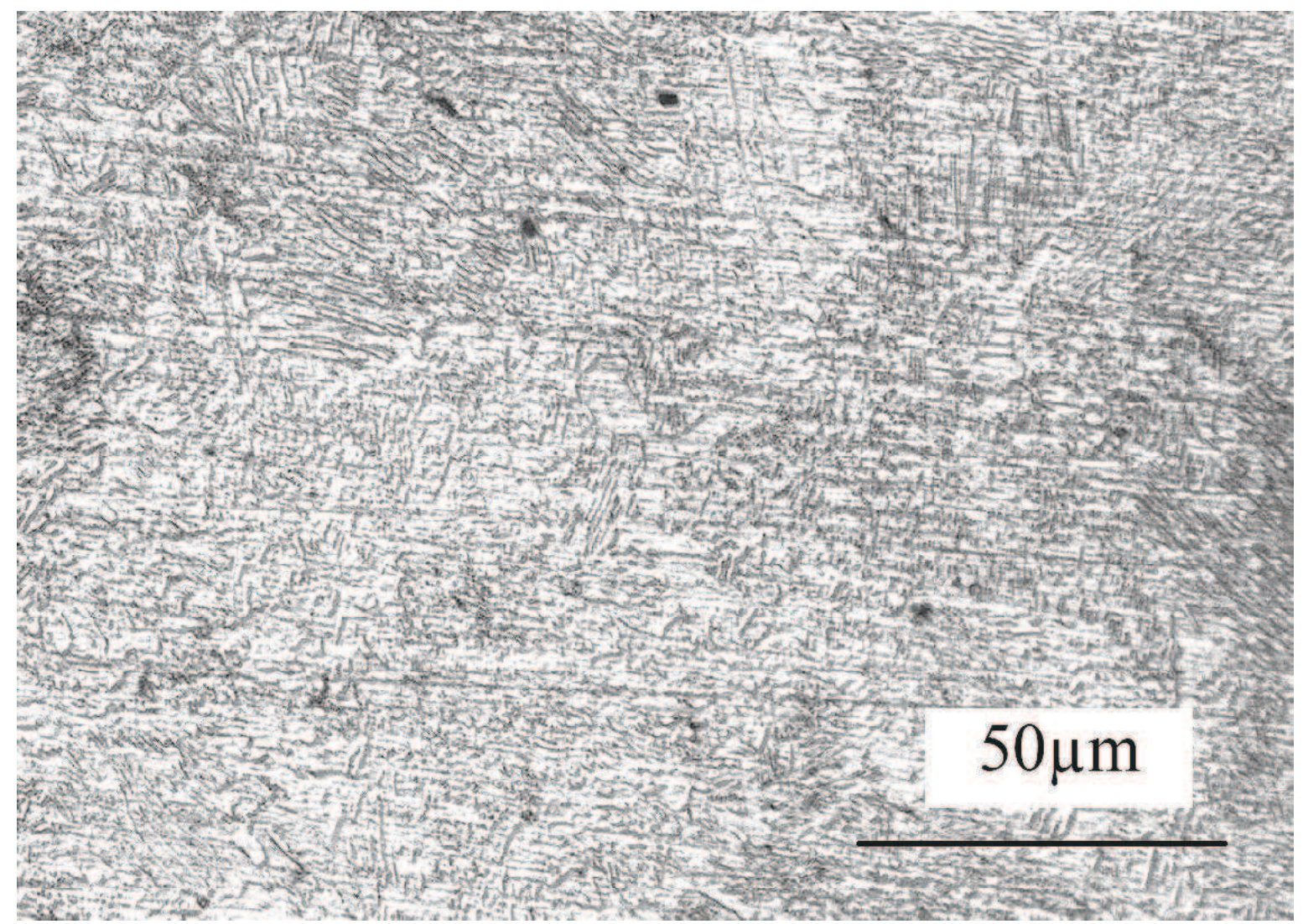

(b) 


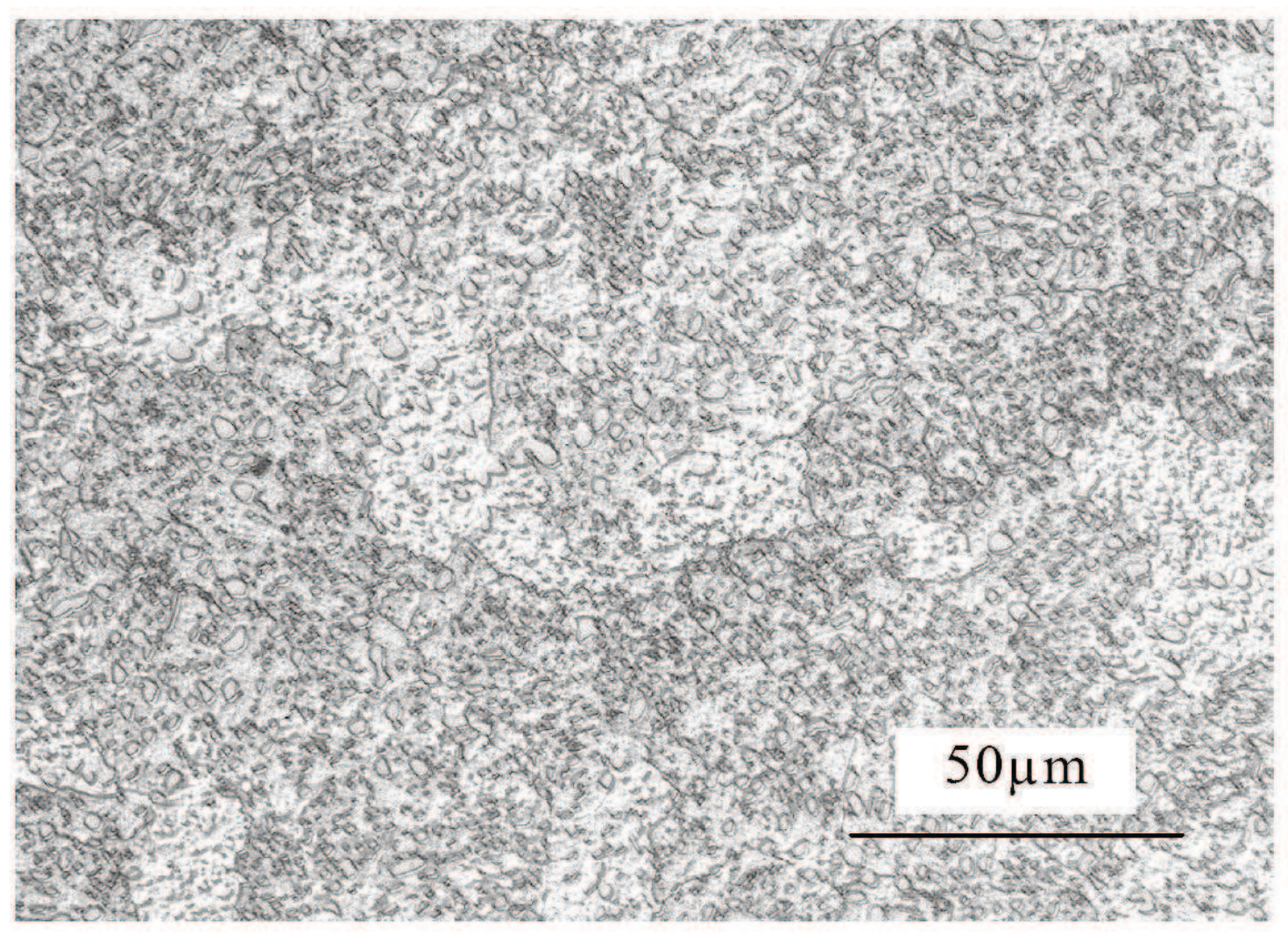

(c)

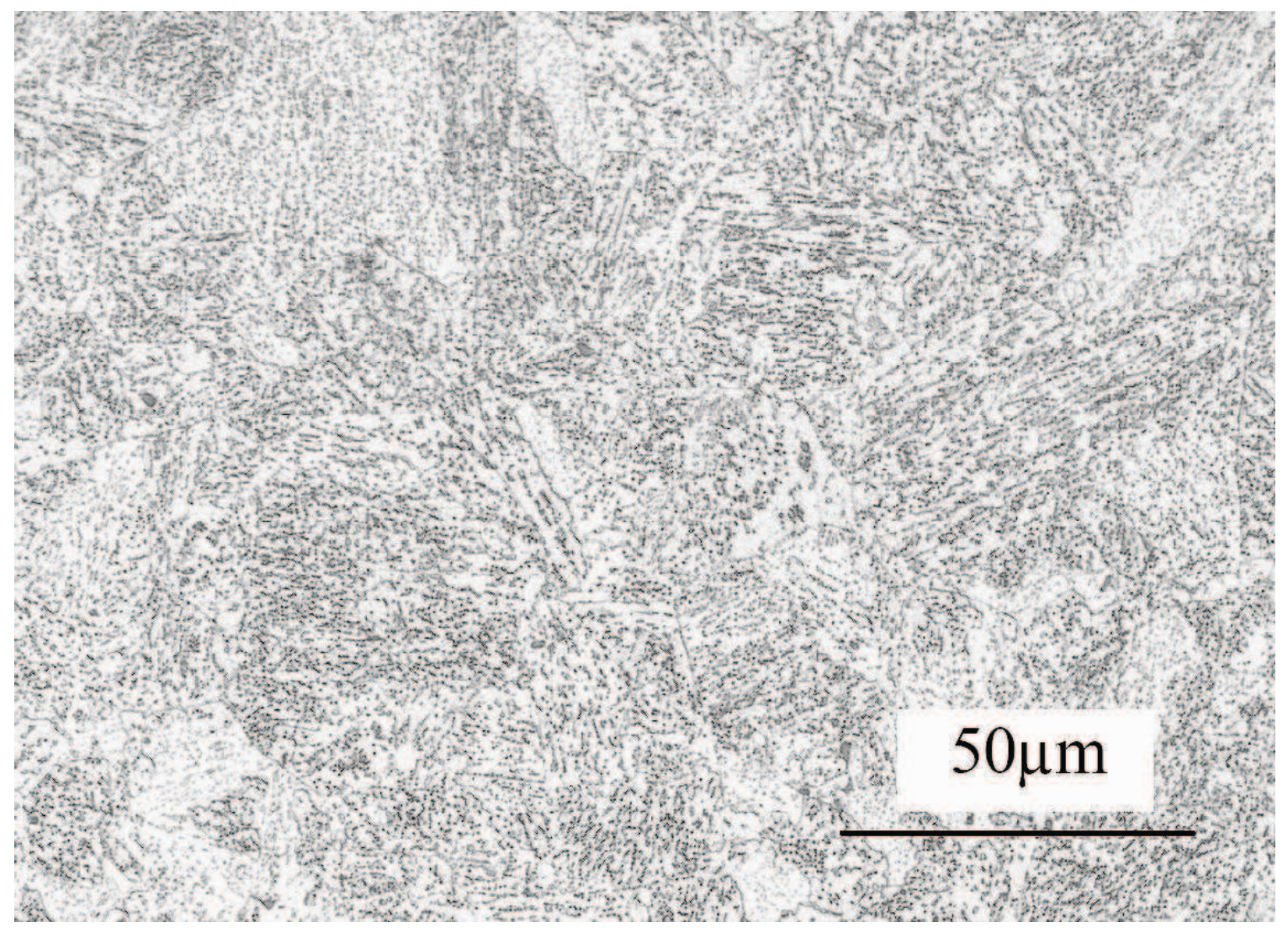

(d) 


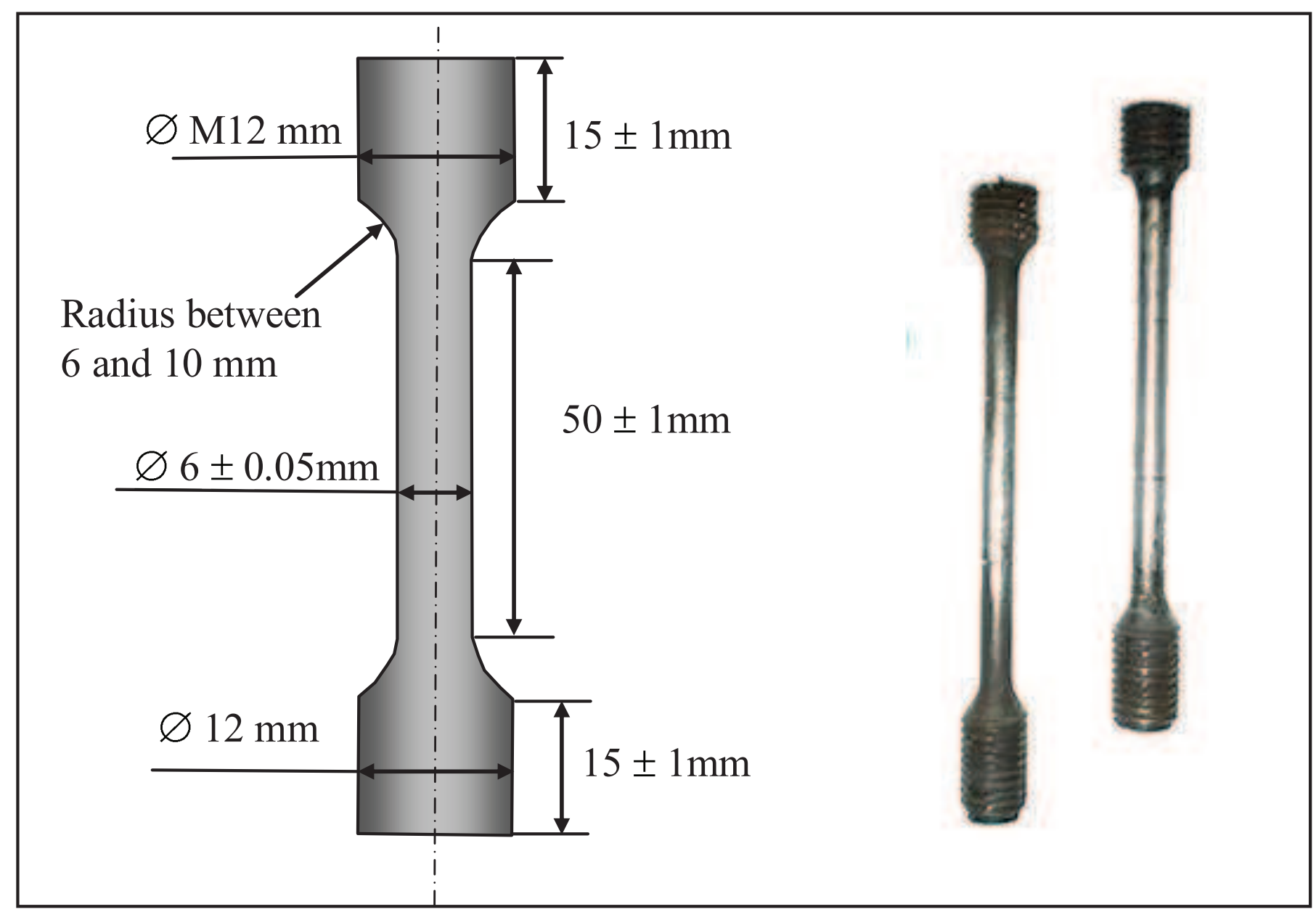




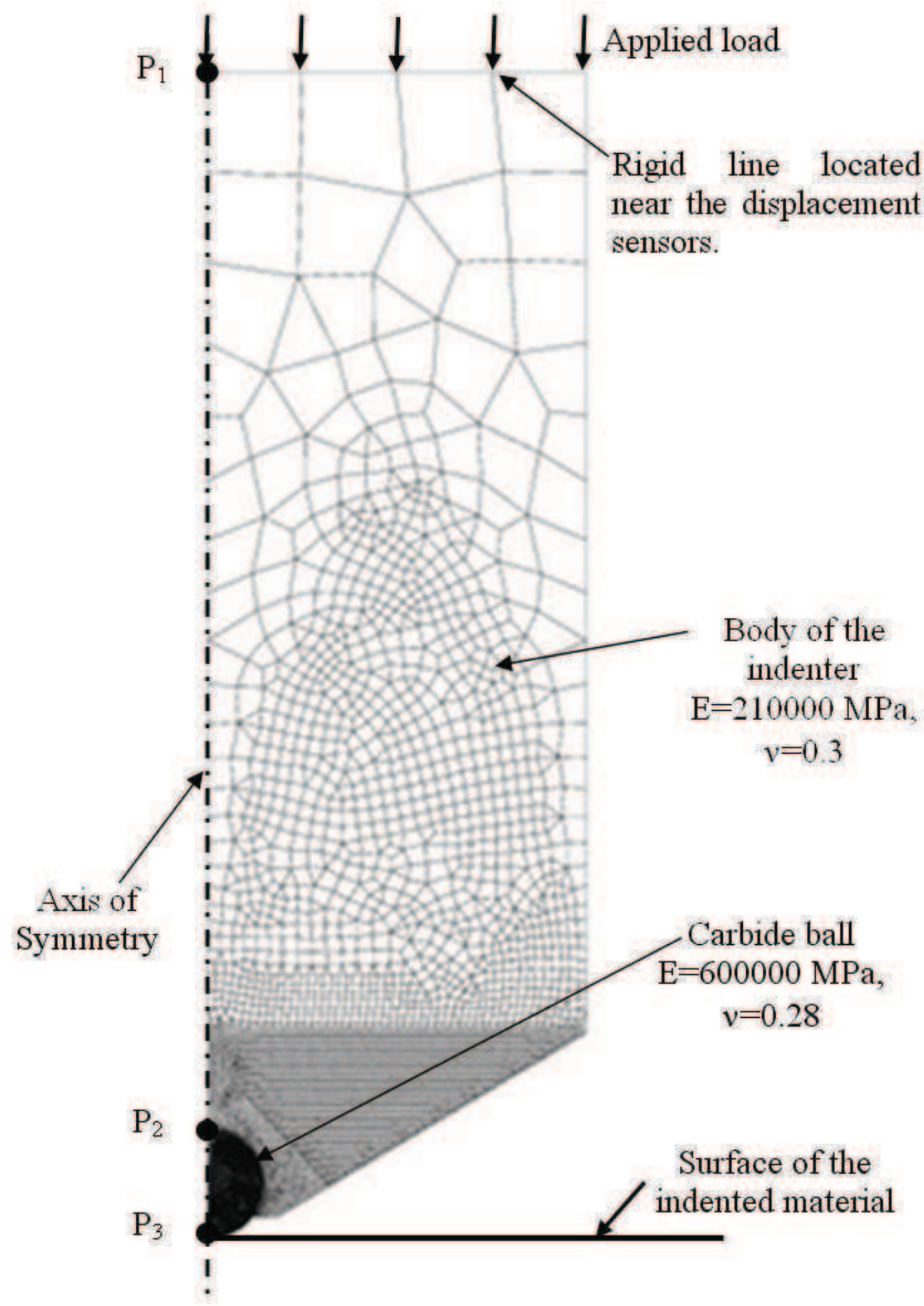




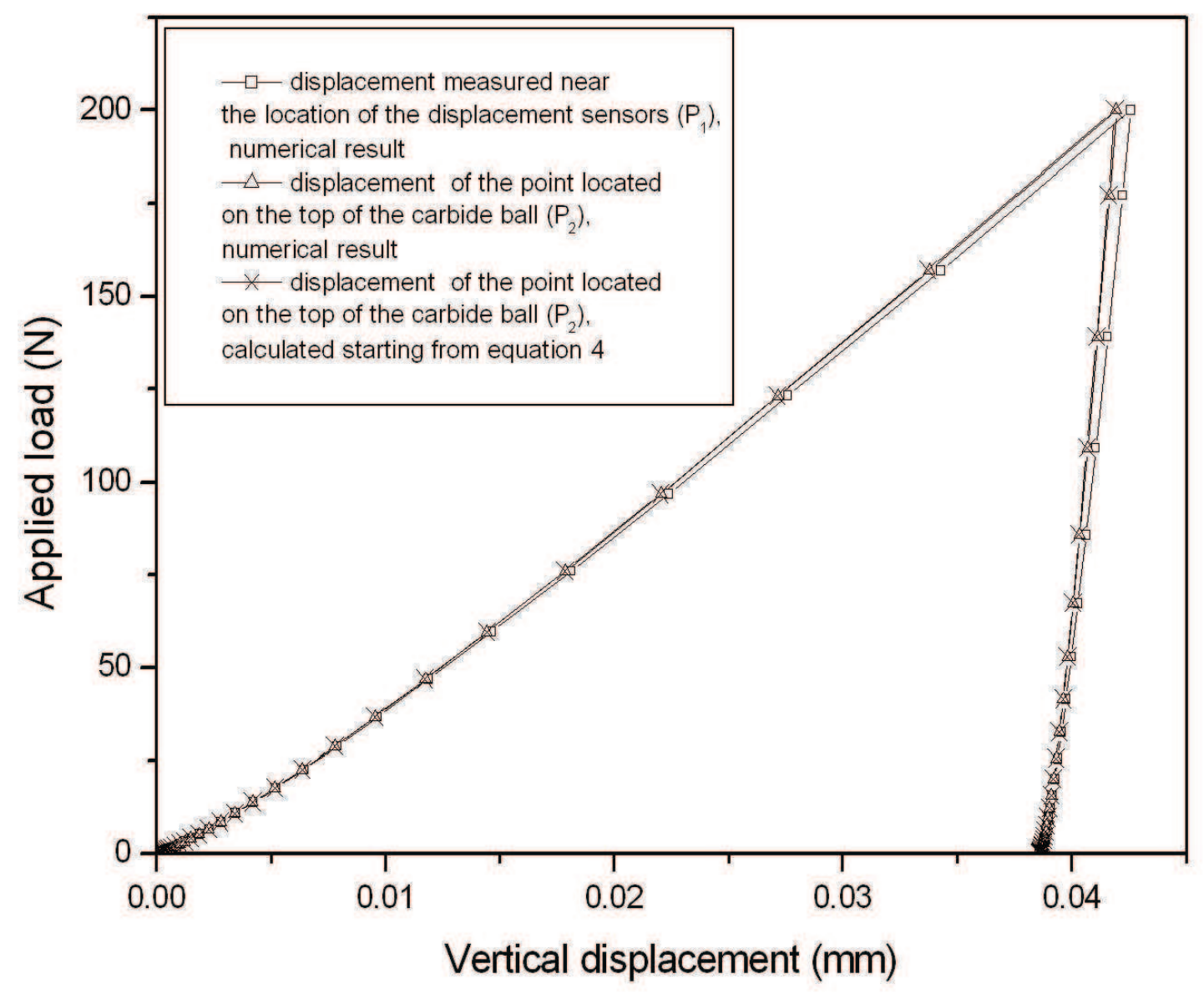


Figure 5

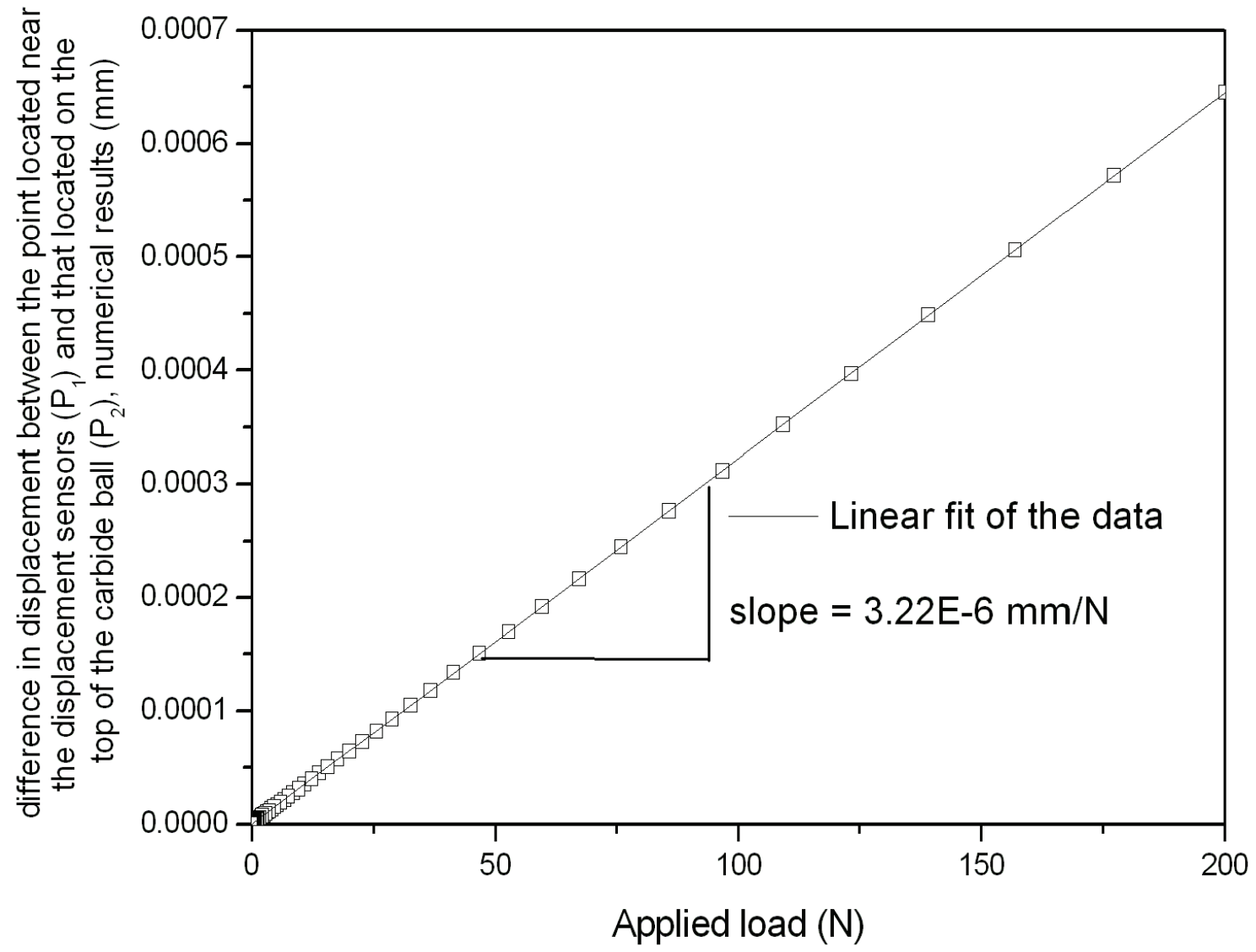




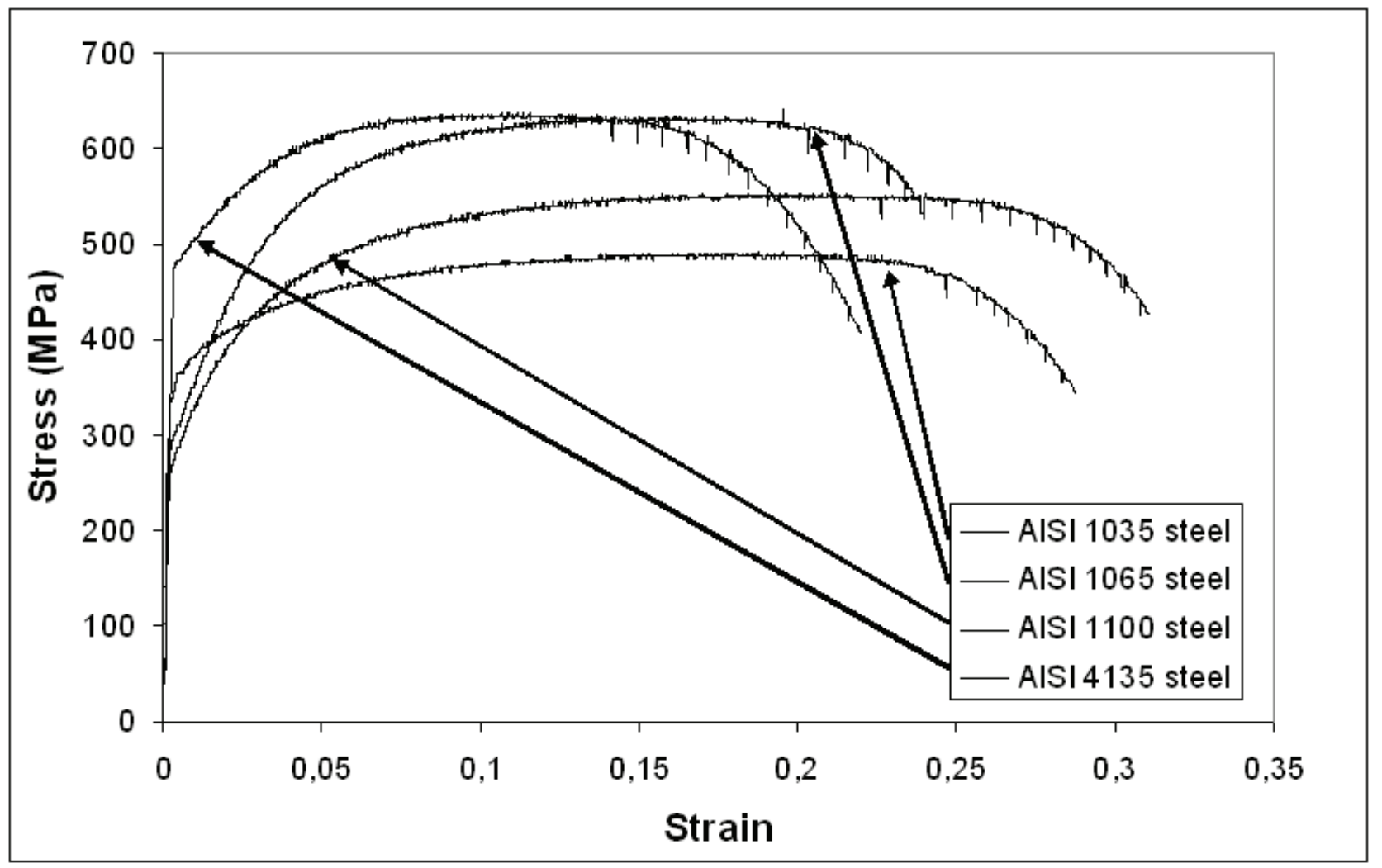




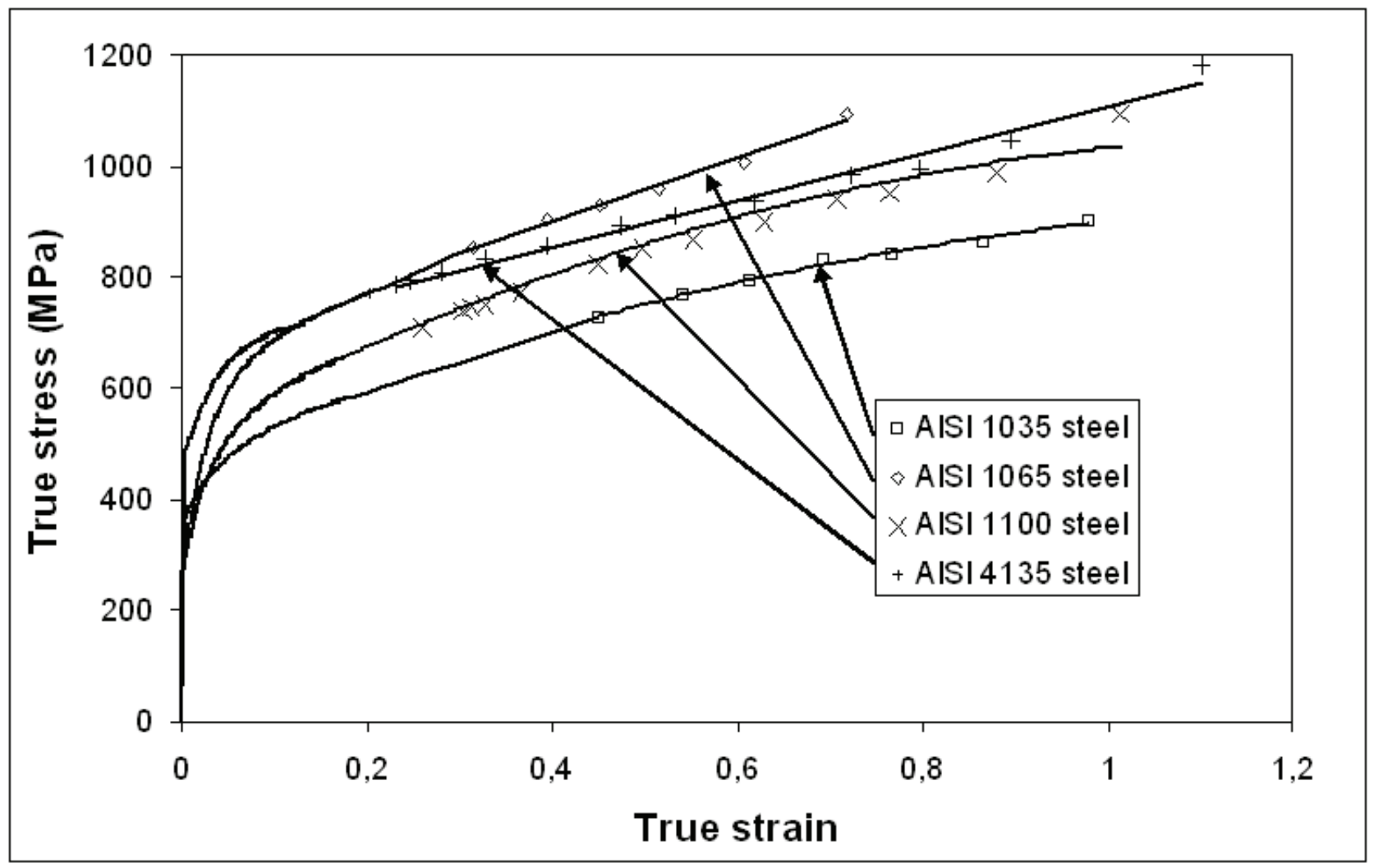



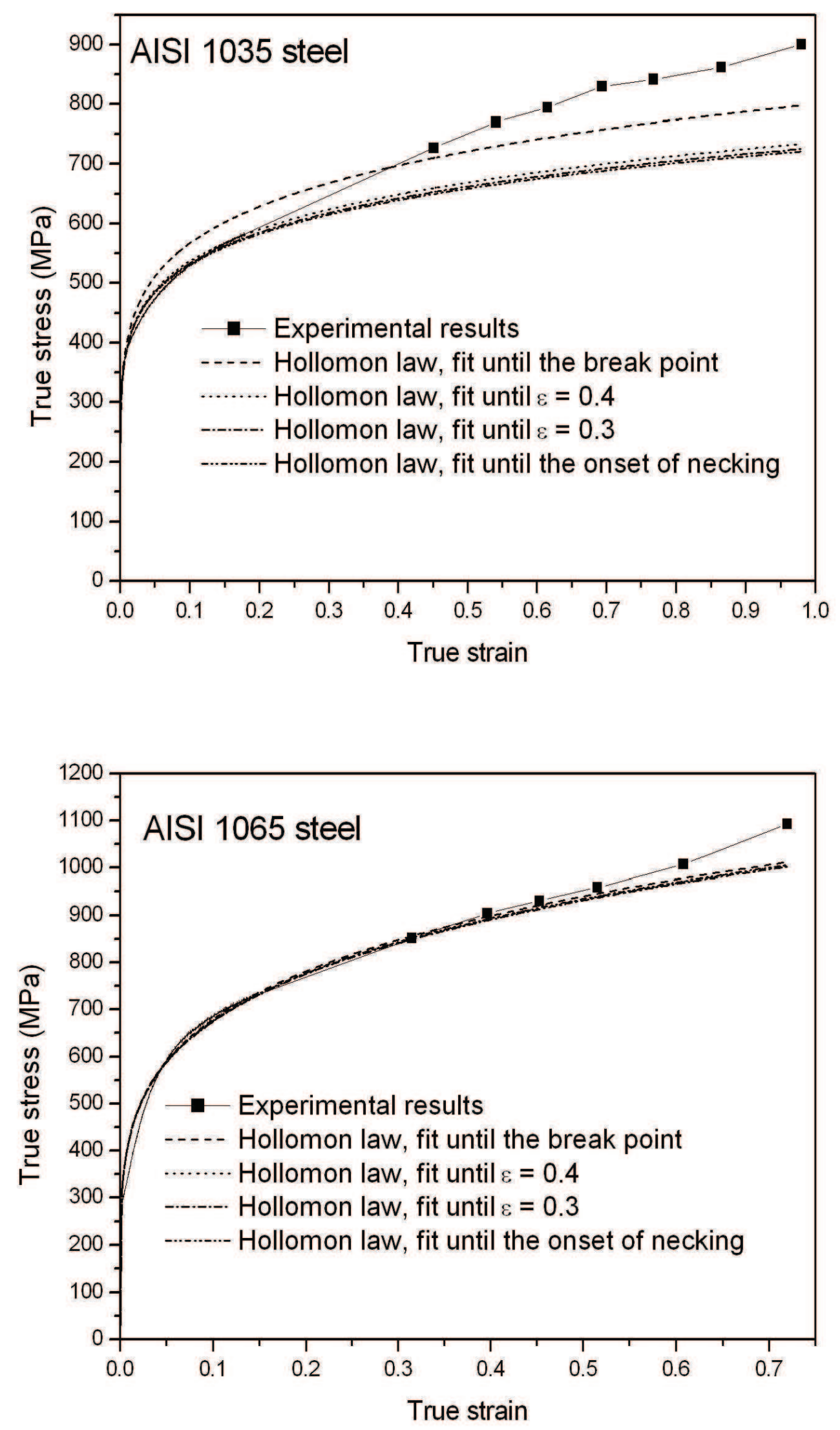

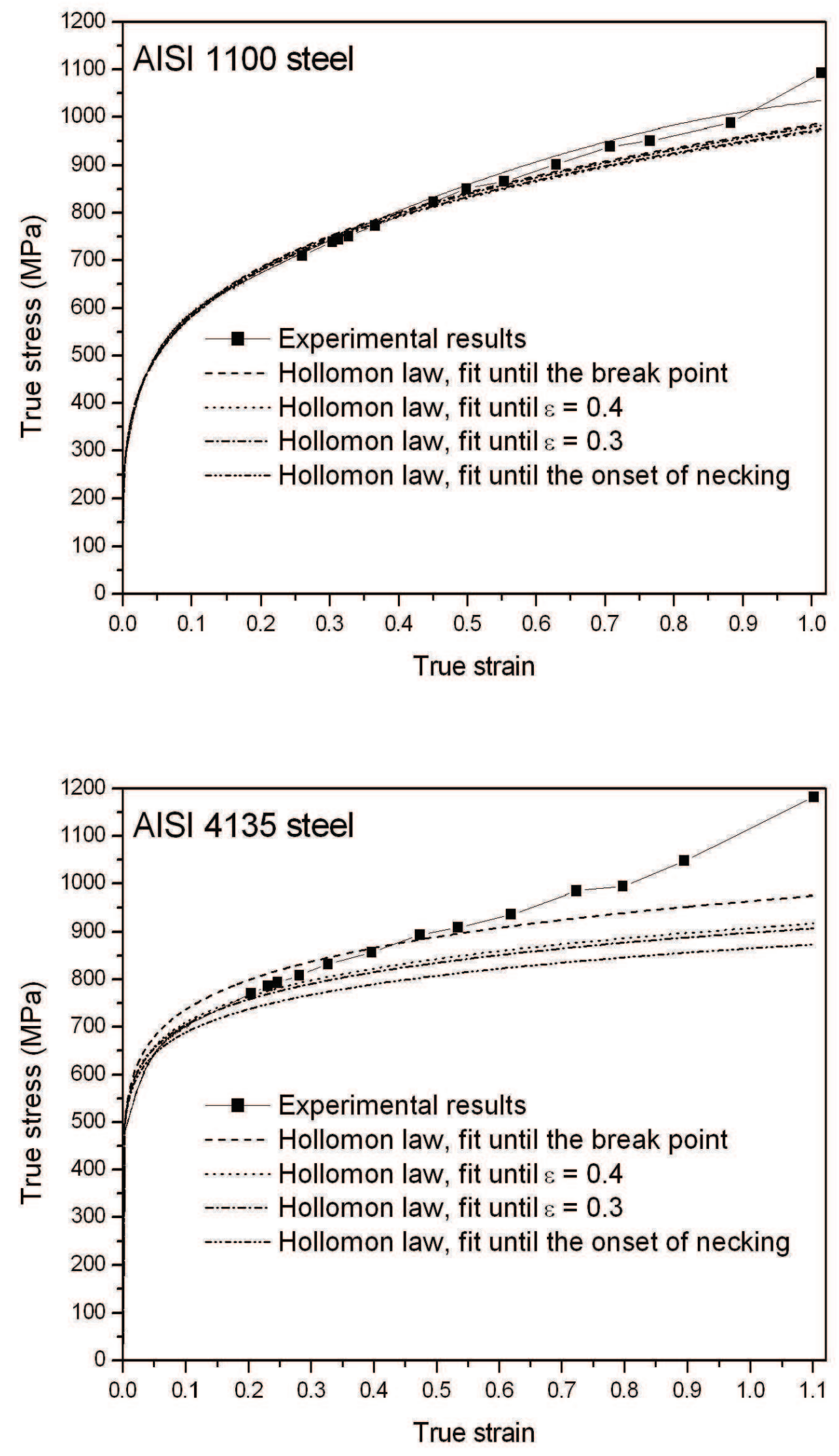


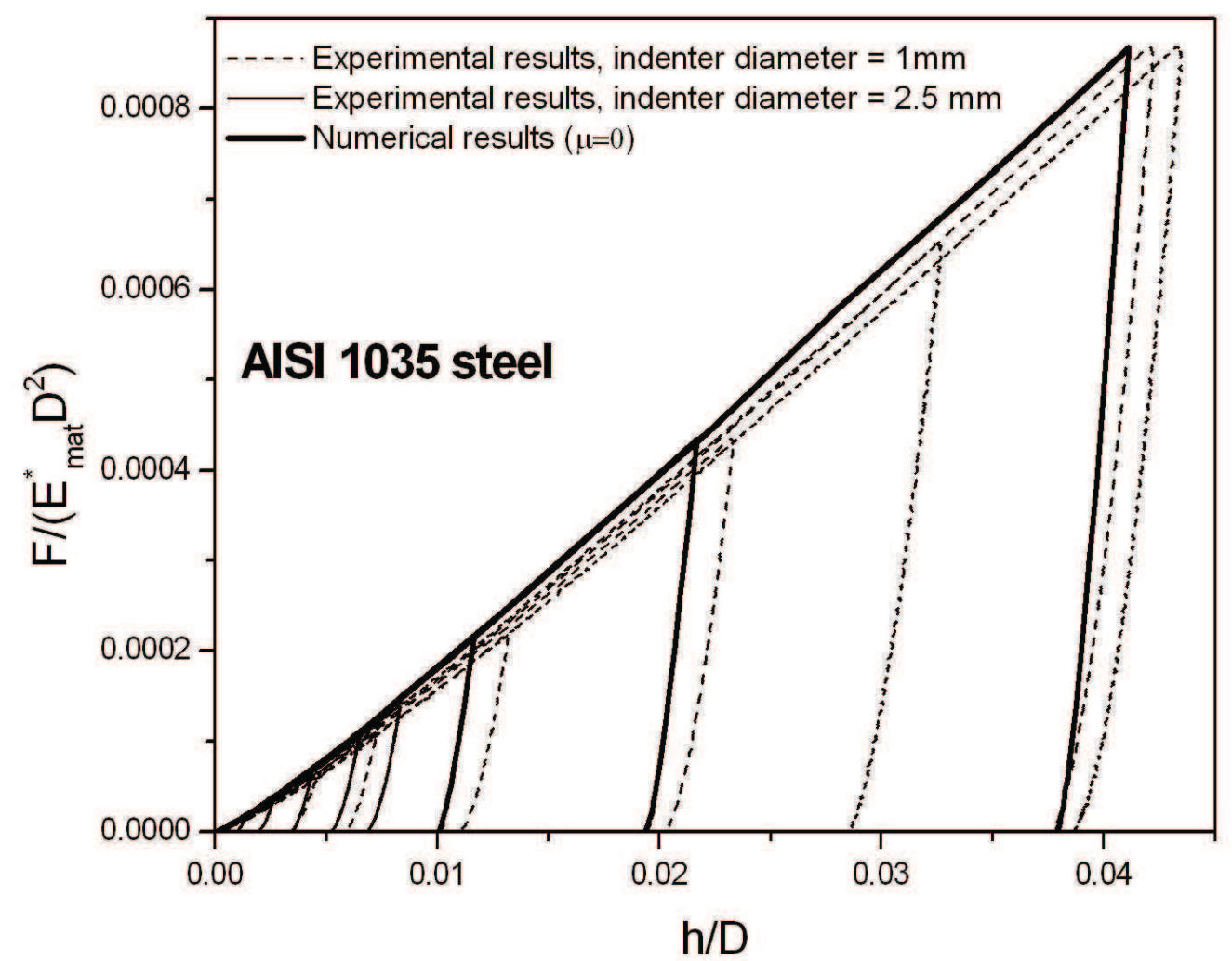

(a)

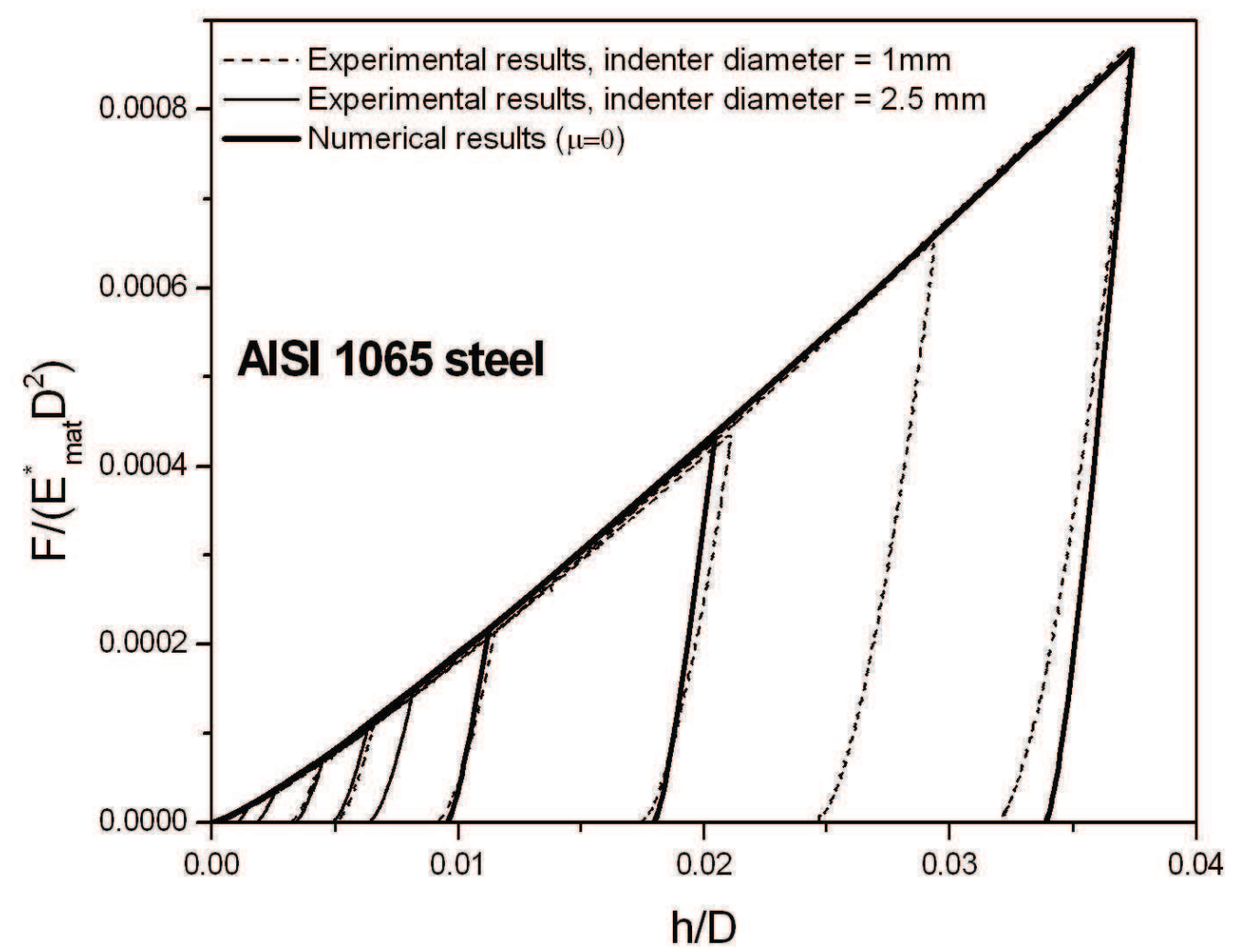

(b) 


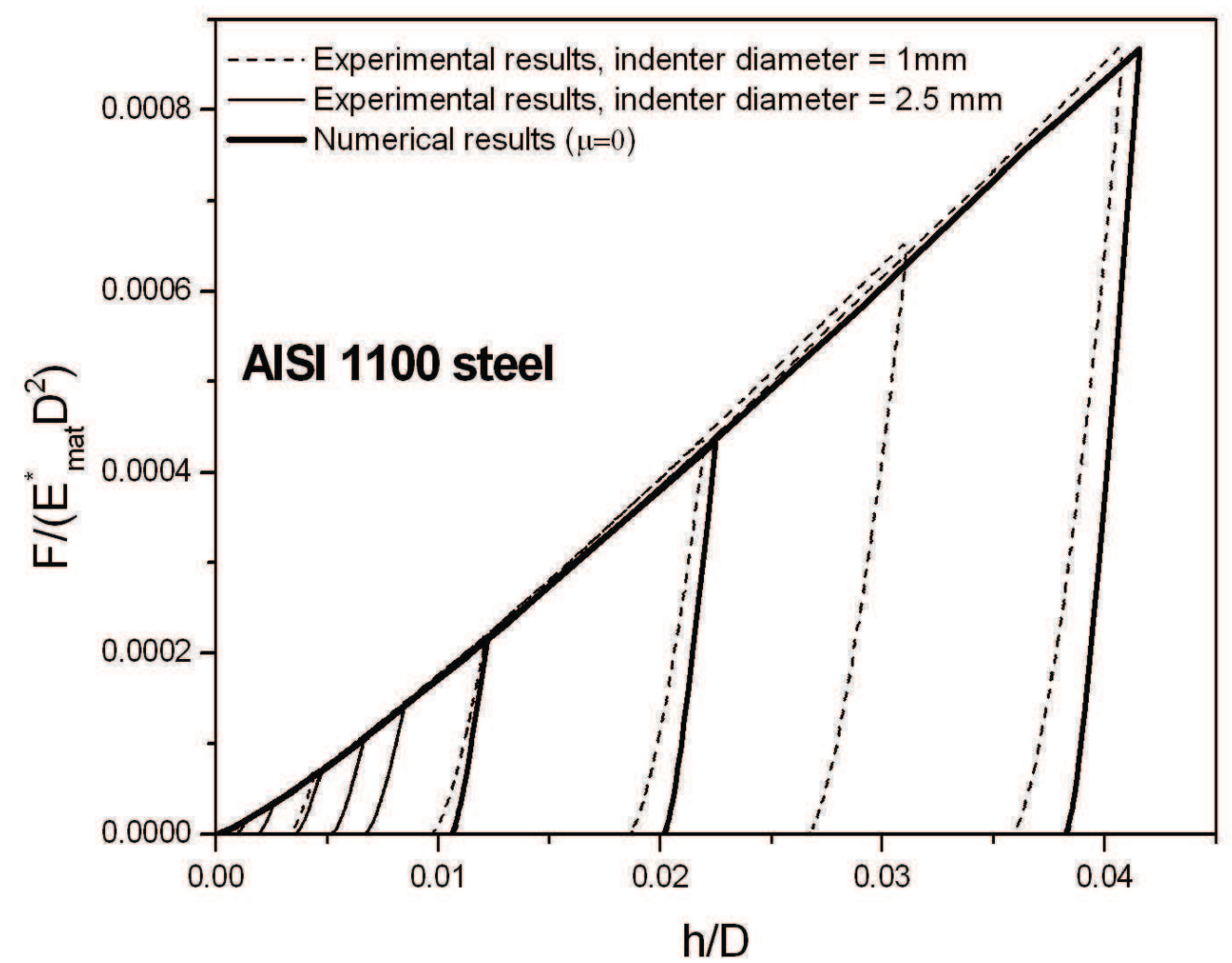

(c)

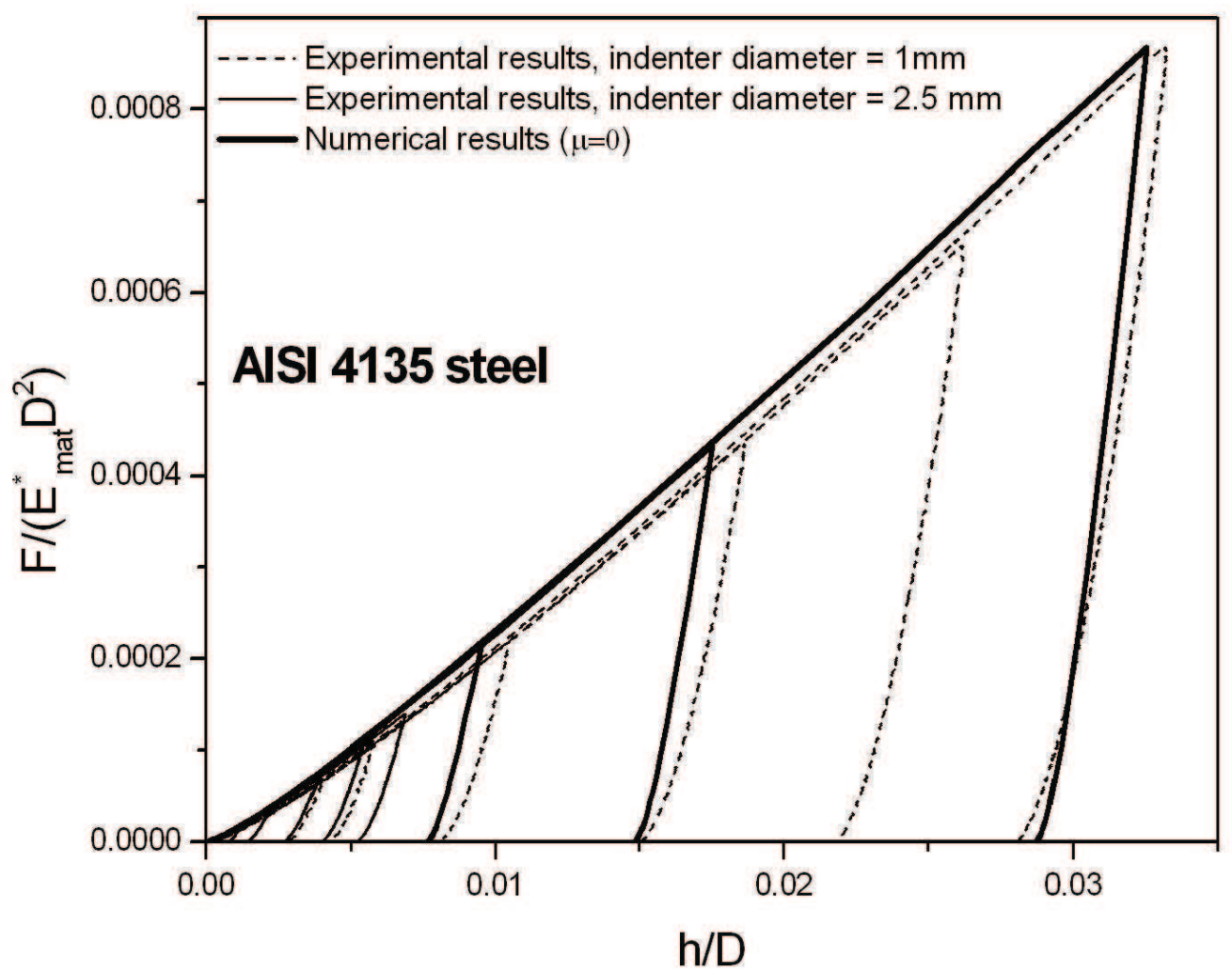

(d) 
Figure 10

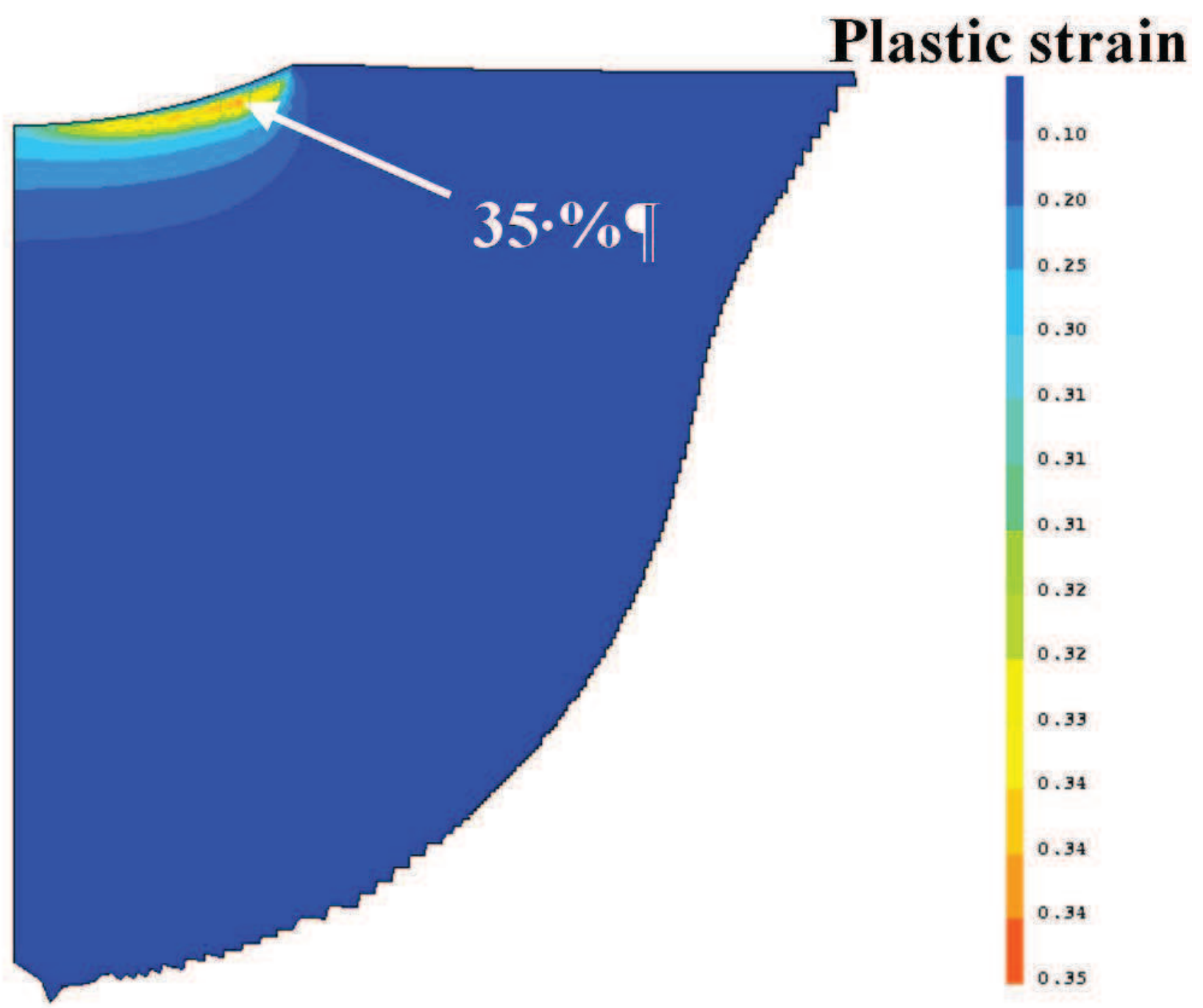

(a) 


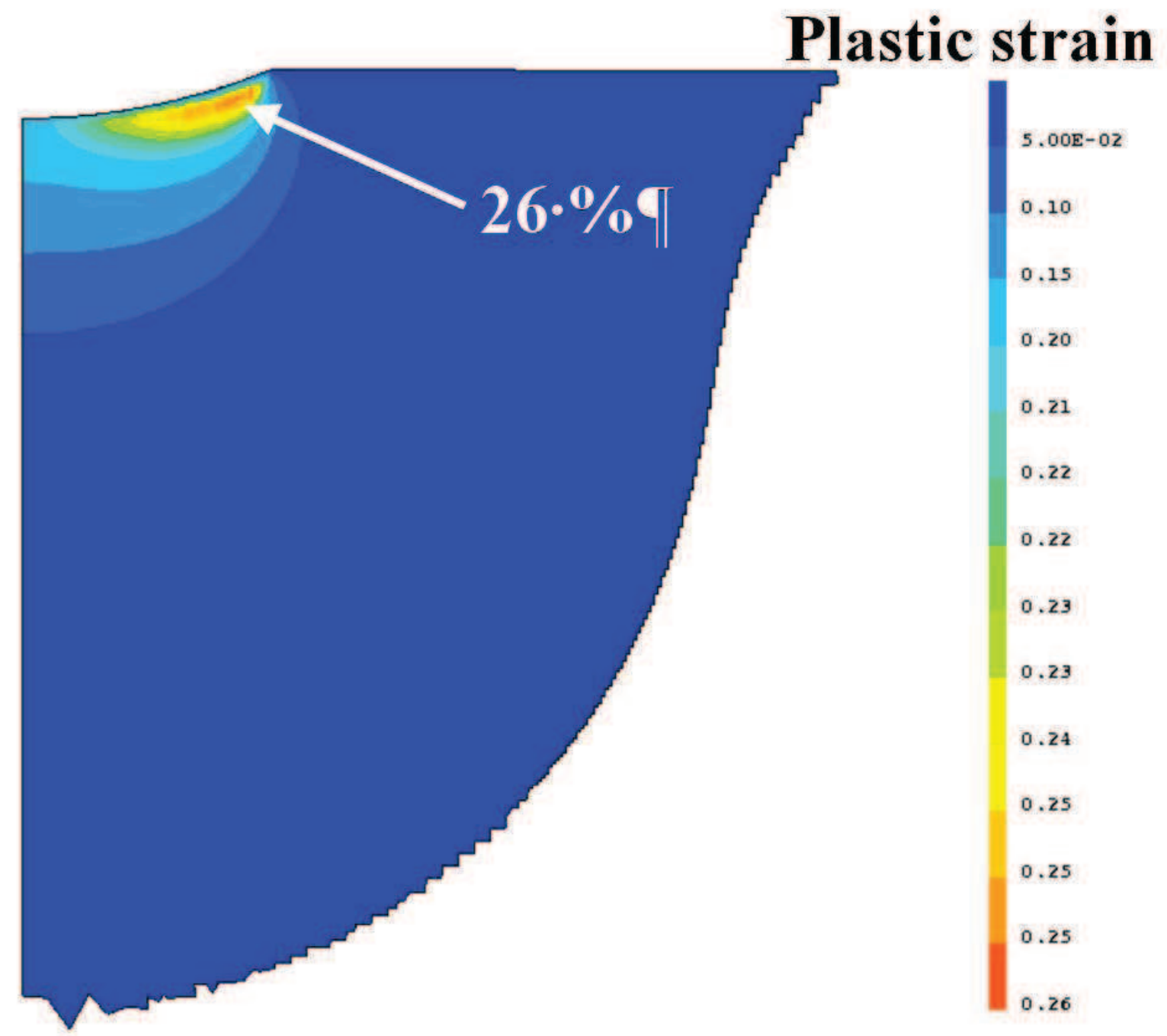

(b) 


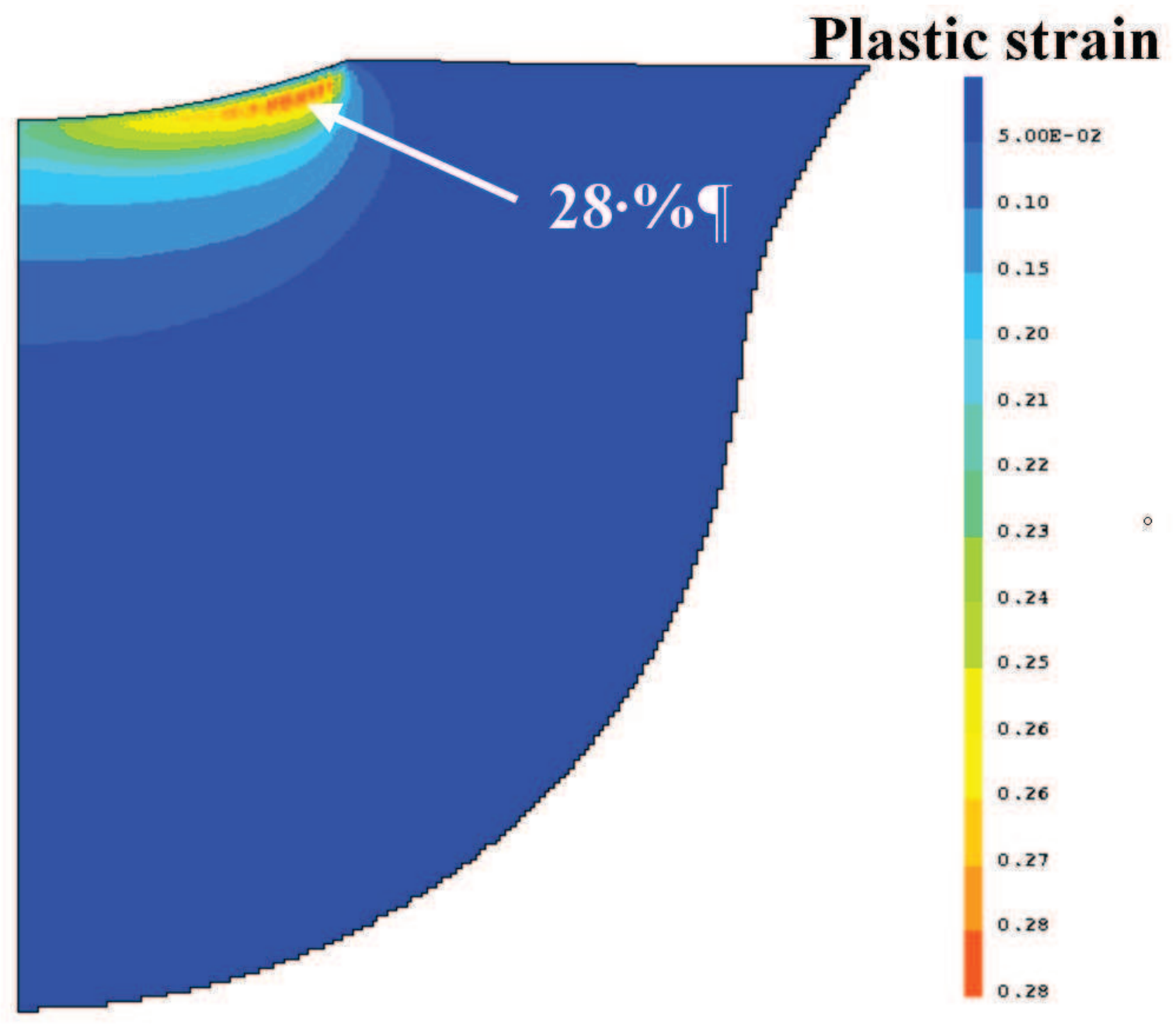

(c) 


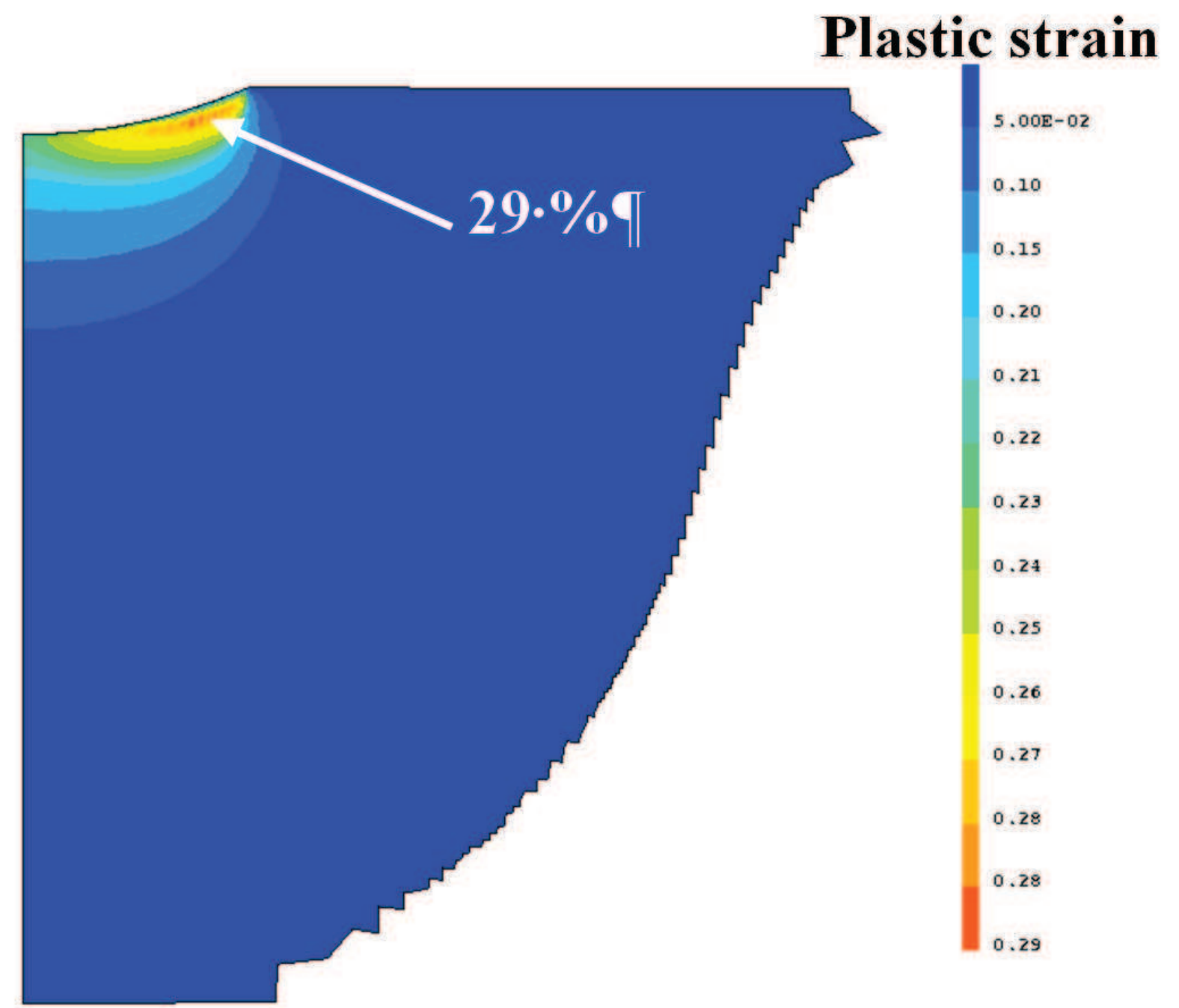

(d) 

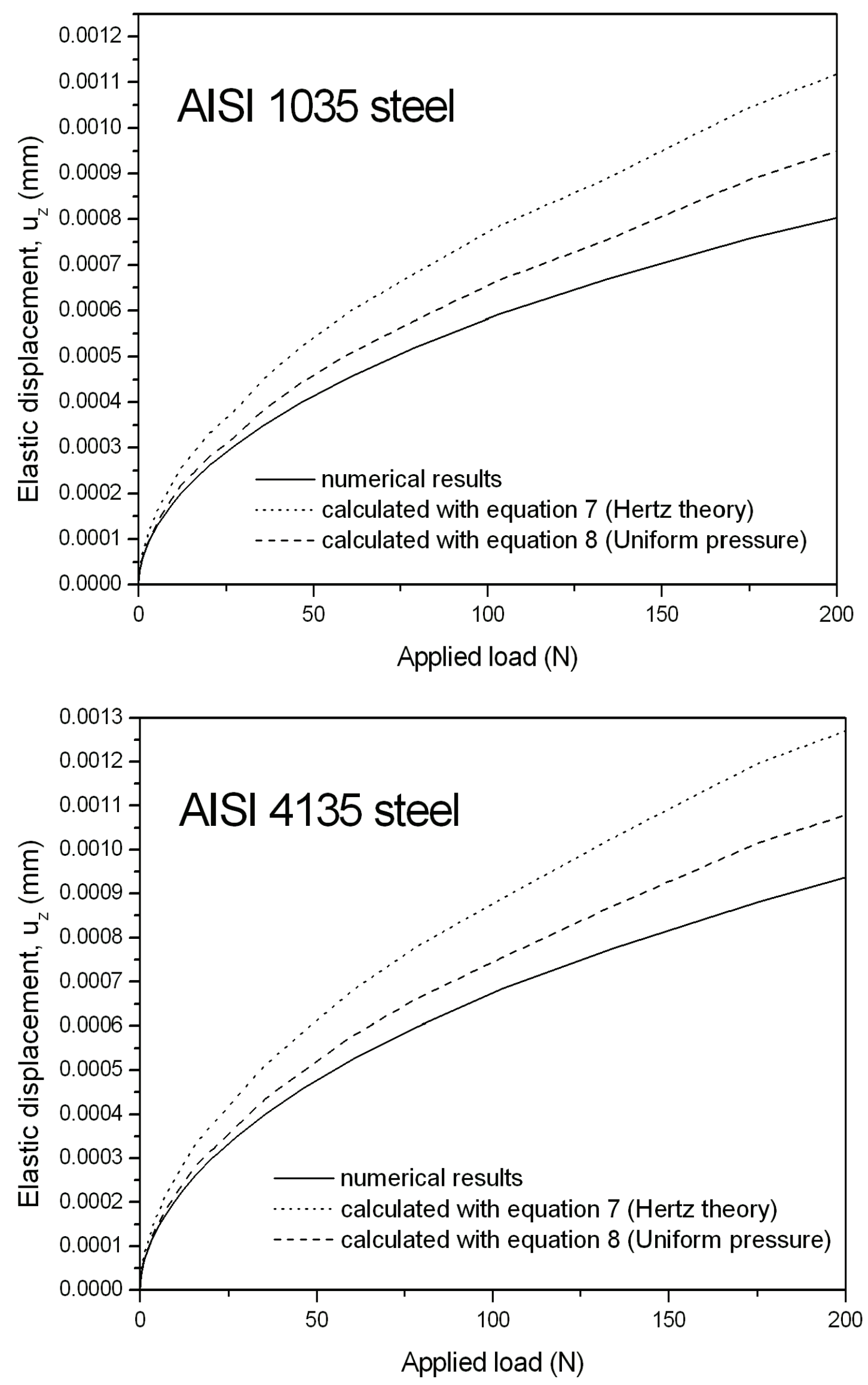

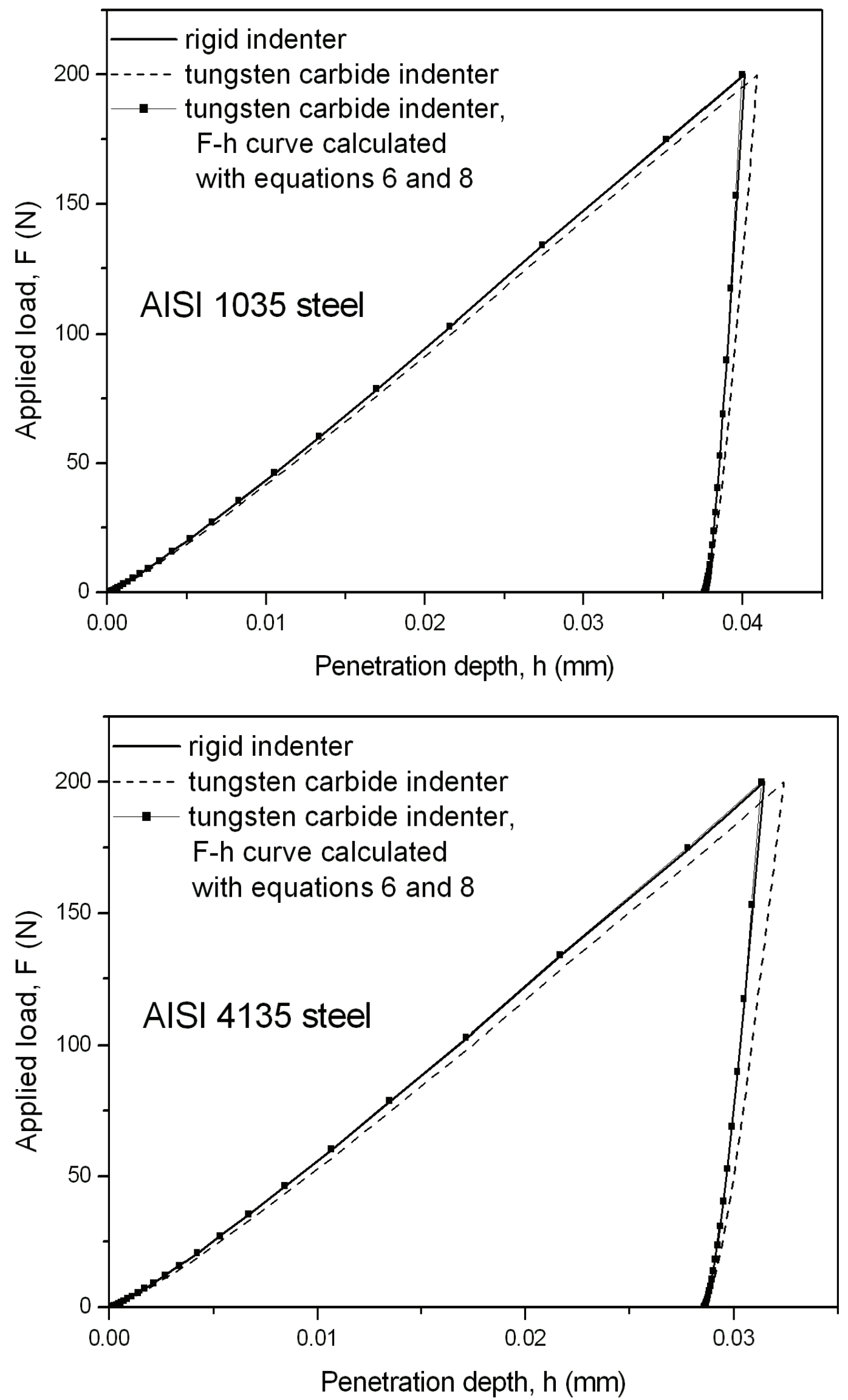


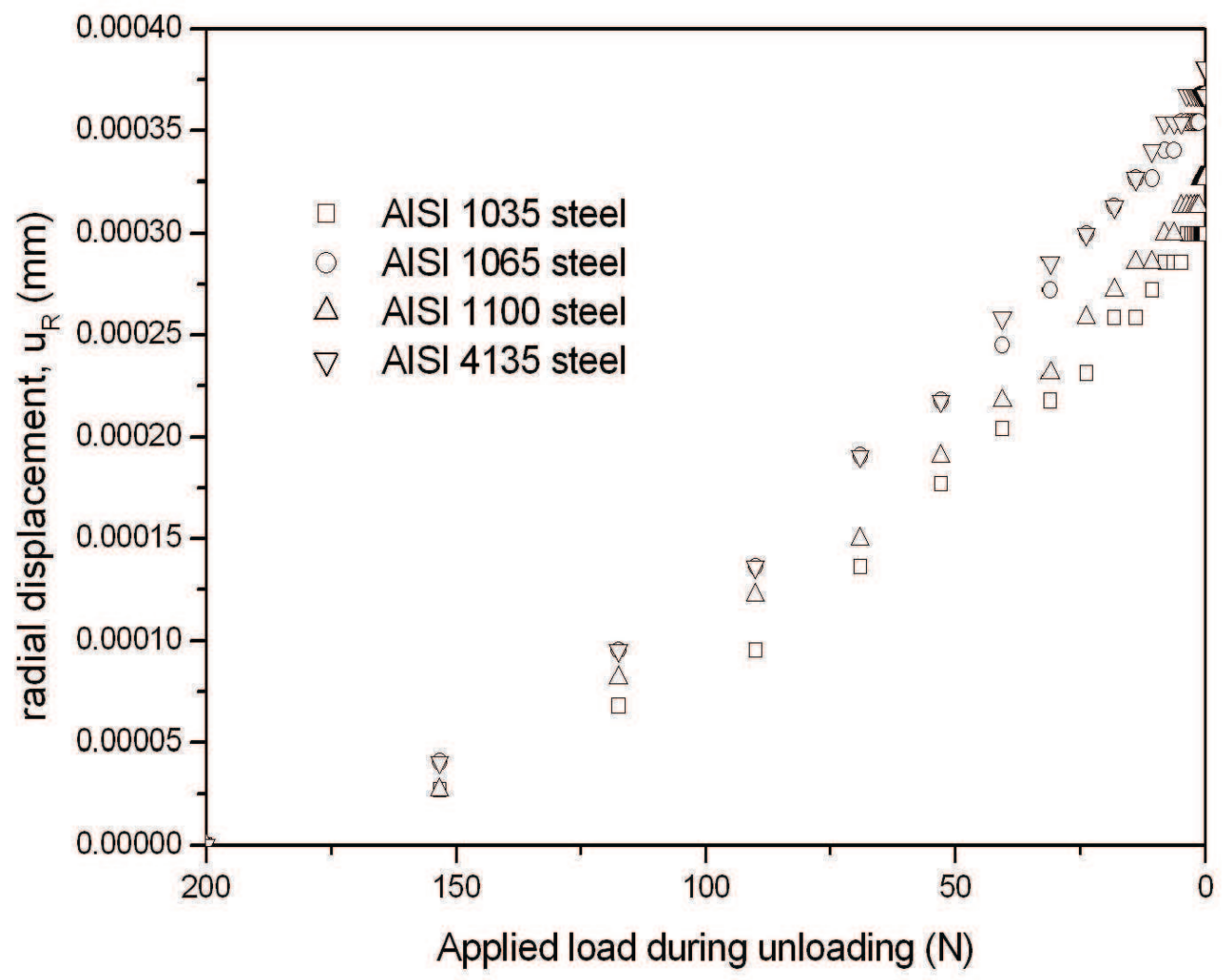




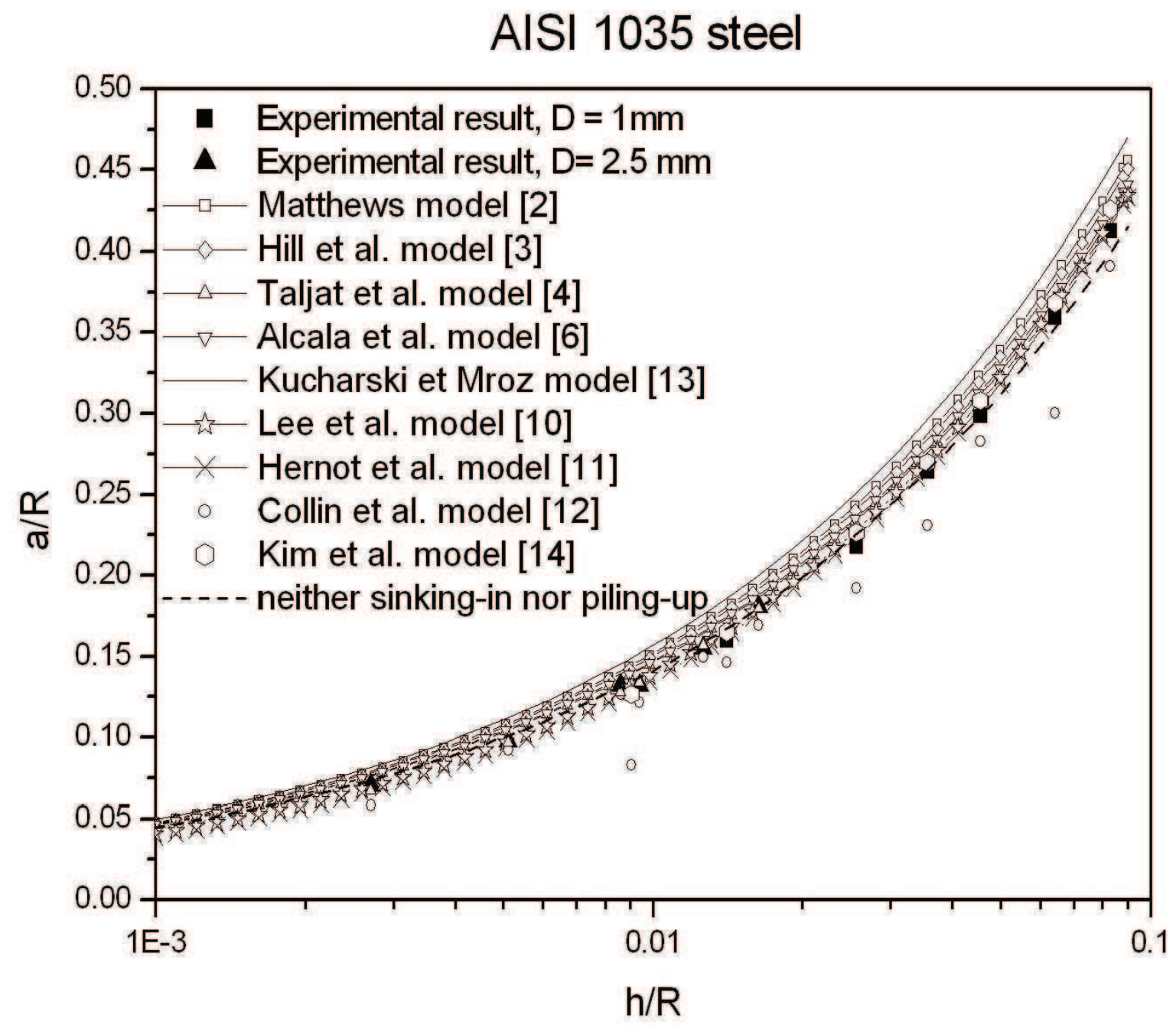




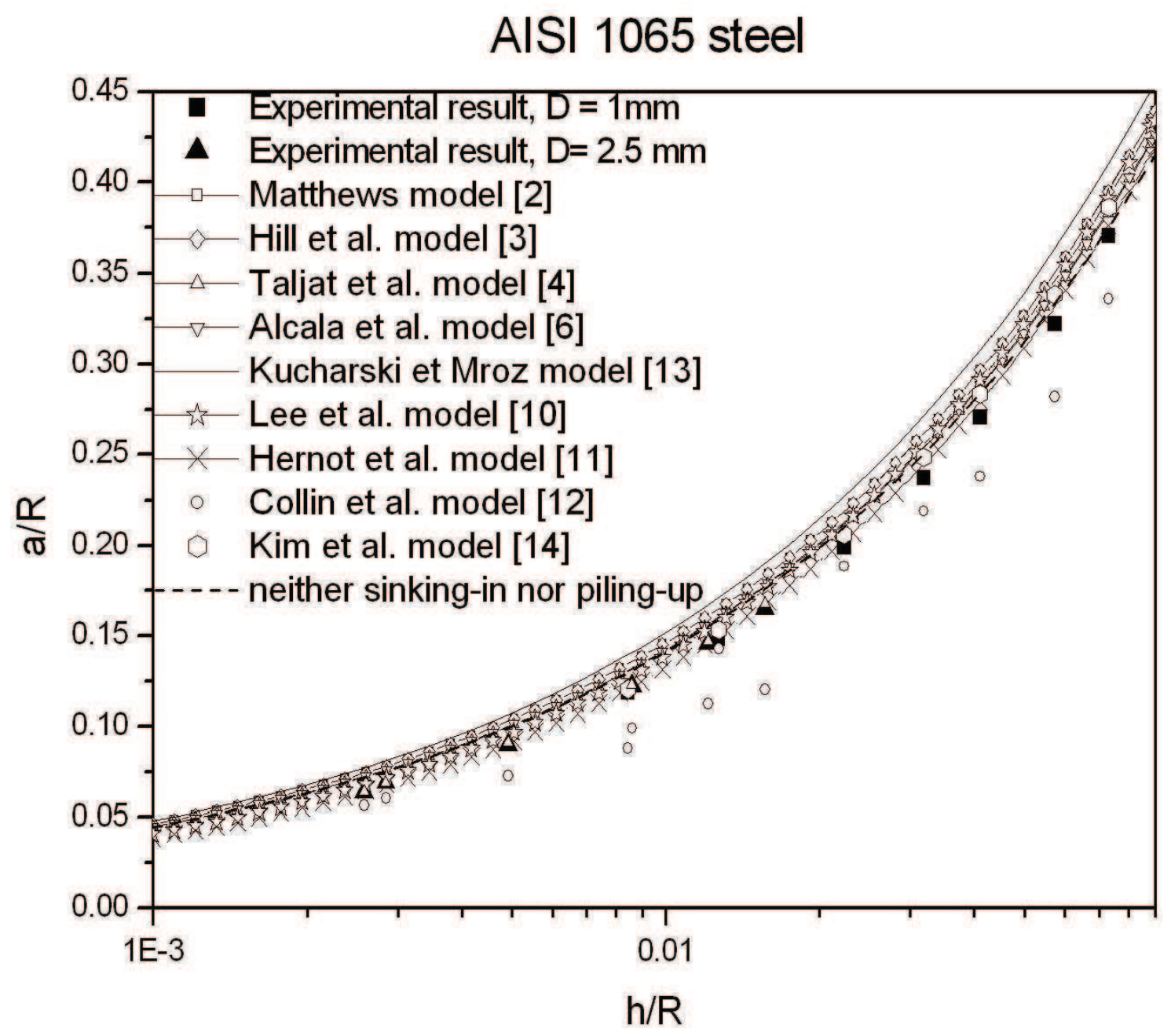




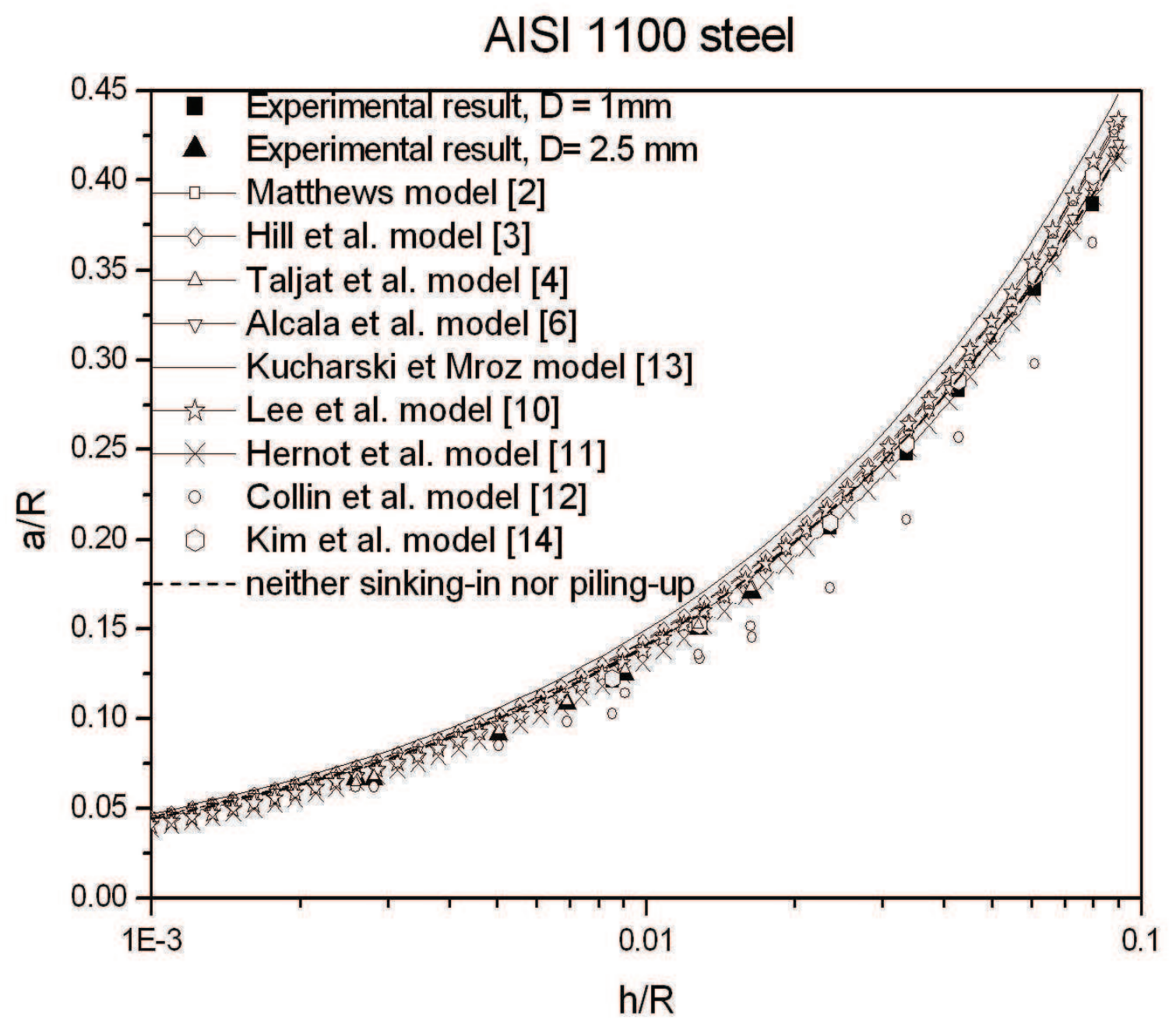




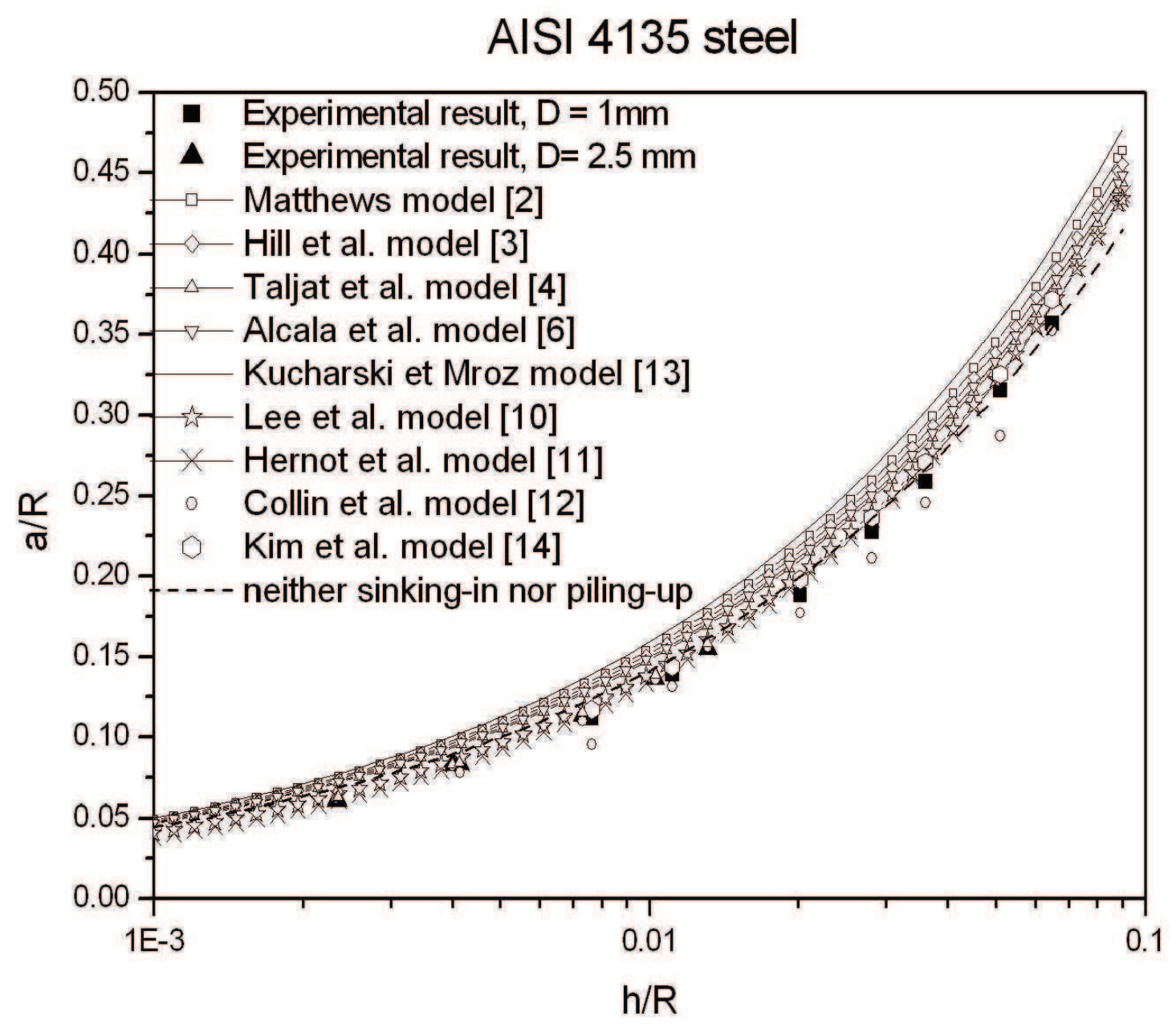




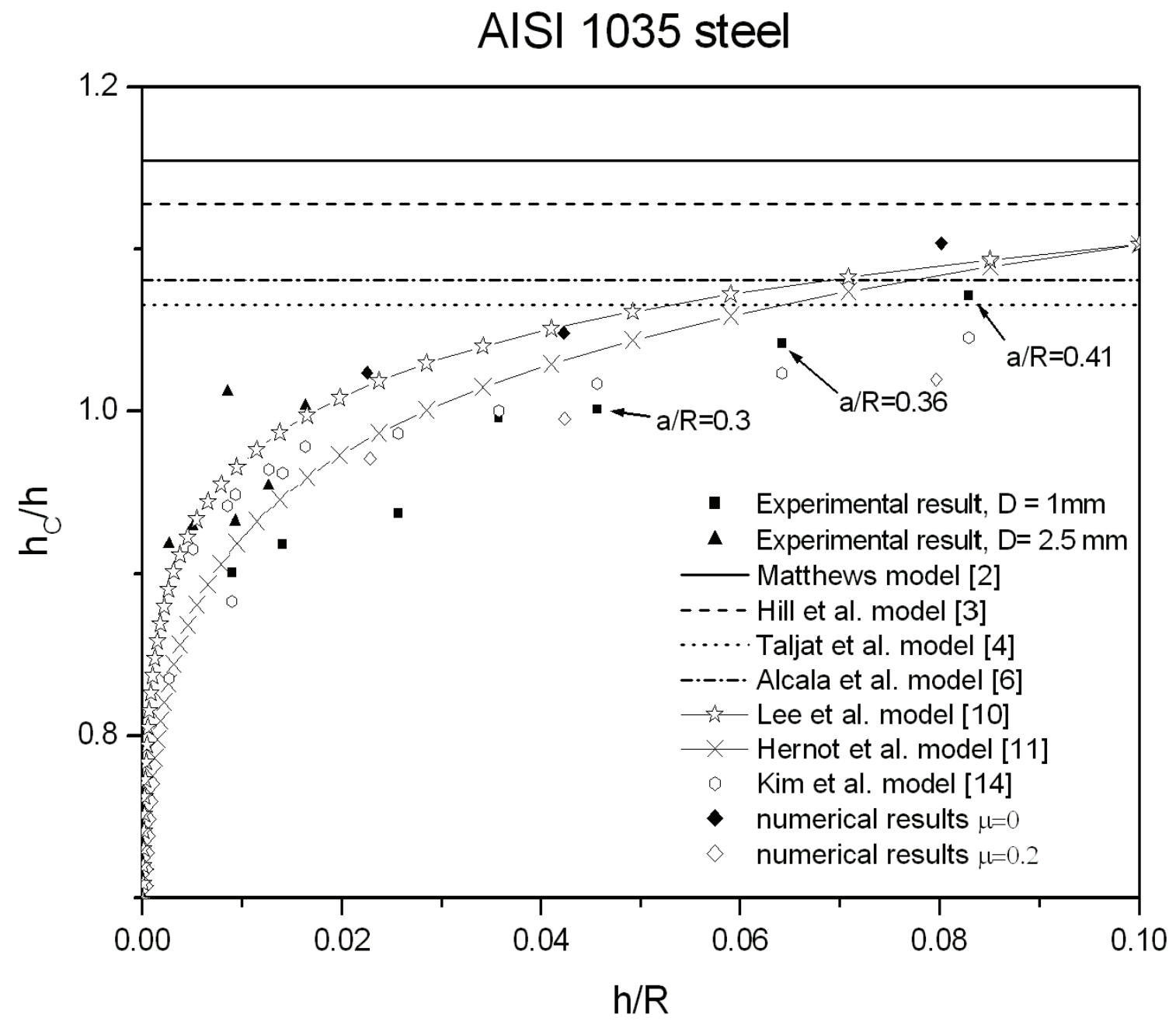




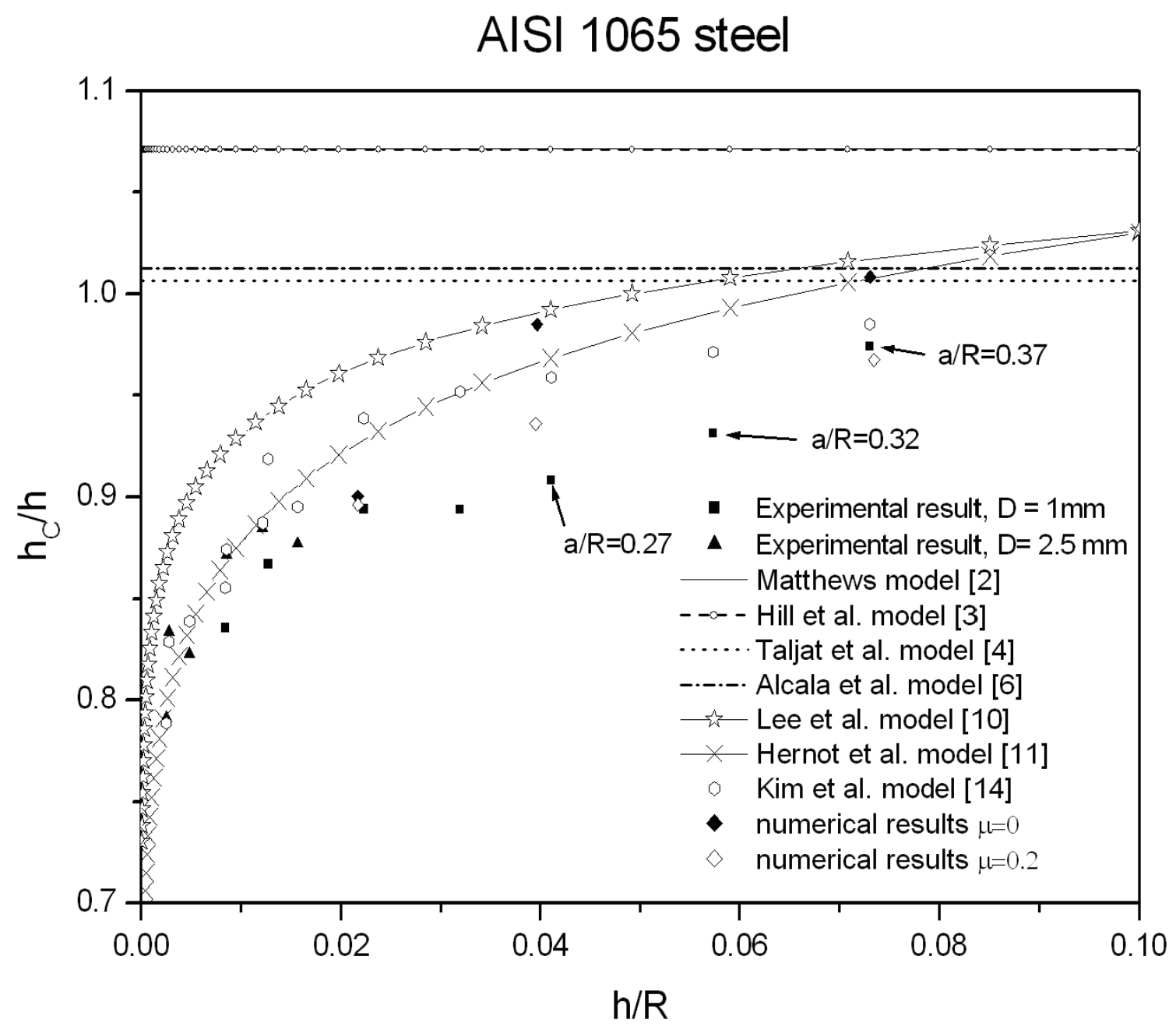




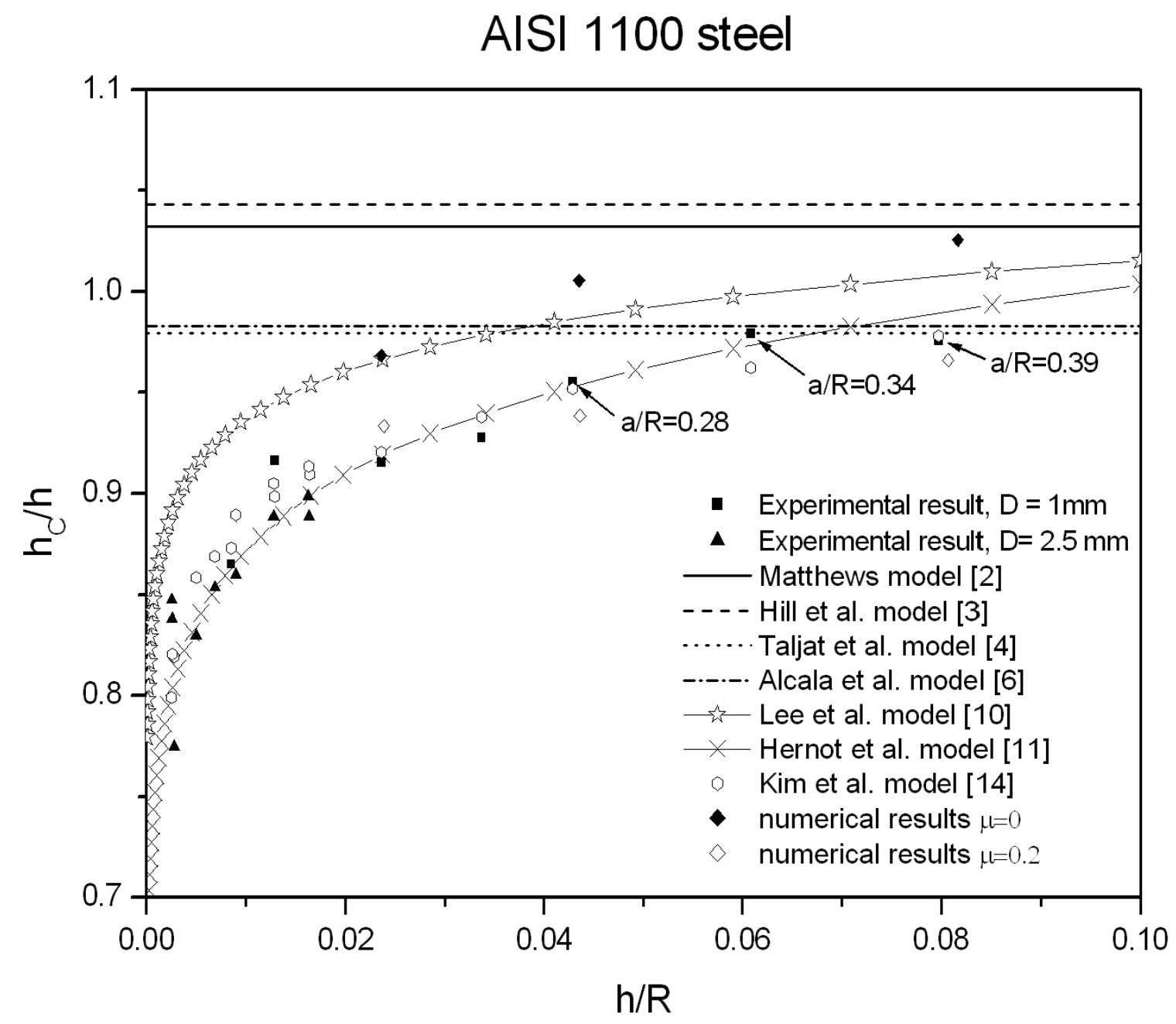


AISI 4135 steel

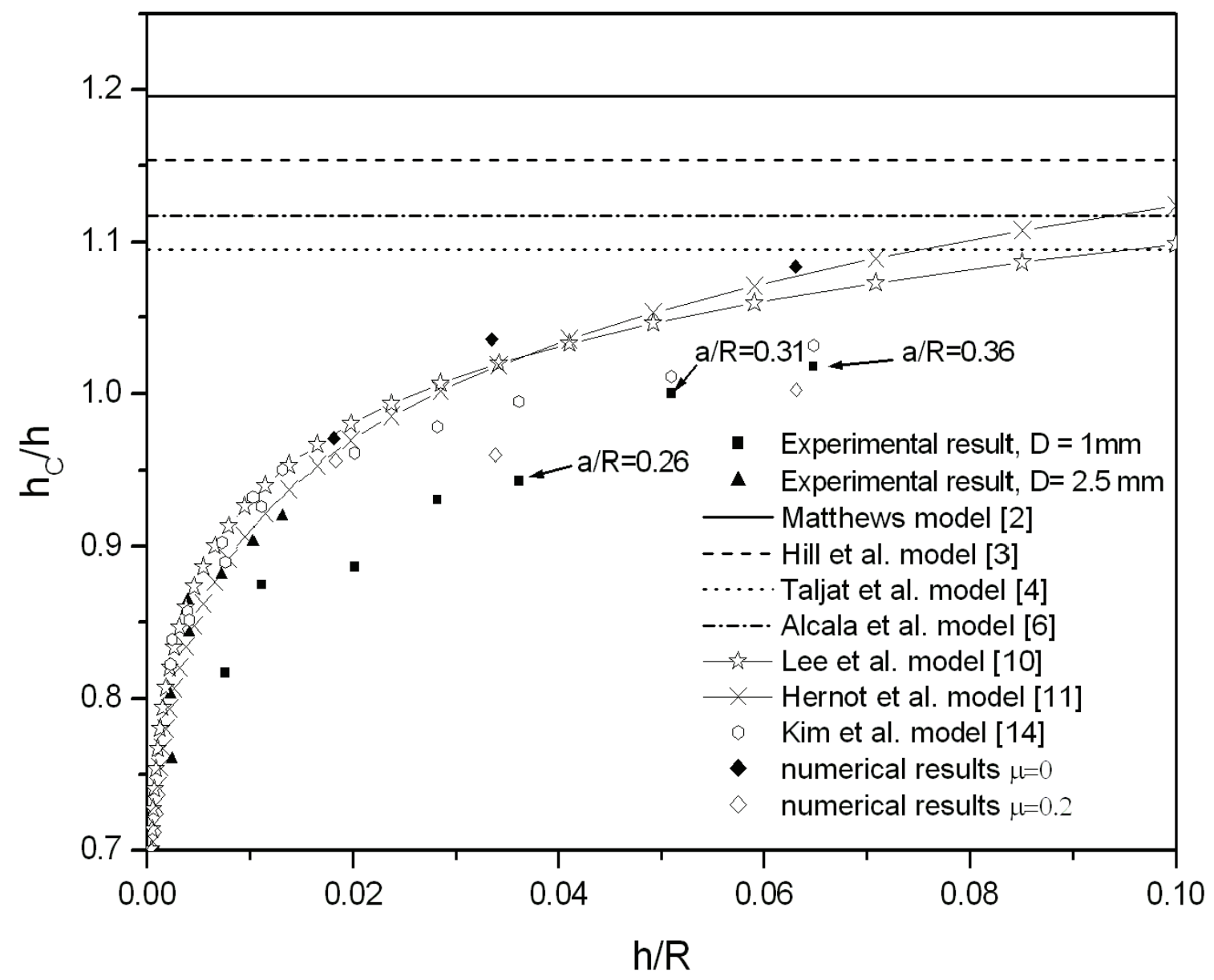


Figure A1

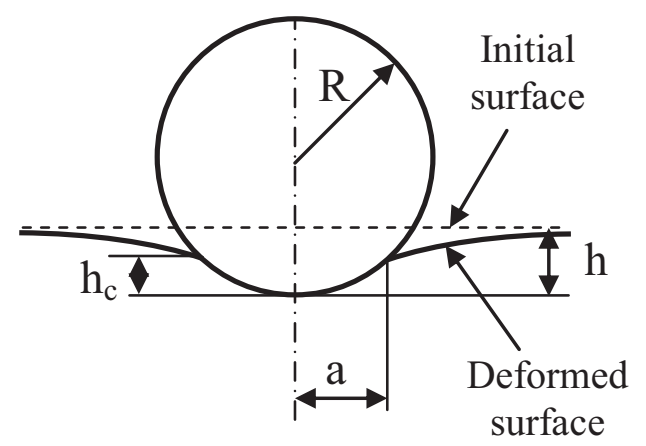

(a)

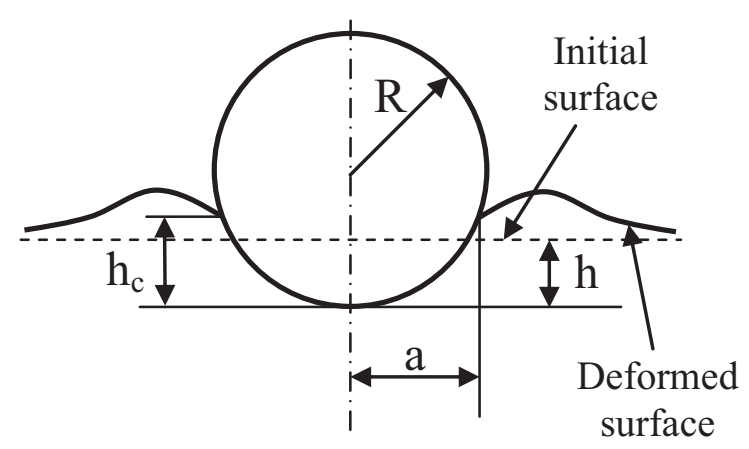

(b) 
Fig. 1: Microstructures of the tested steels after polishing and nital etching, (a) AISI 1035, spheroidized ; (b) AISI 1065, spheroidized ; (c) AISI 1100, spheroidized and (d) AISI 4135, spheroidized

Fig. 2: specimens used for the tensile test

Fig. 3: Mesh of the indenter (carbide ball of radius $\mathrm{R}=0.5 \mathrm{~mm}$ )

Fig. 4: Comparison between the numerical displacement of the point located on the top of the carbide ball and the displacement calculated starting from the load frame compliance given in Table 2.

Fig. 5: Numerical value of the load frame compliance.

Fig. 6: Engineering tensile curves

Fig. 7: True stress-strain curves obtained by using the Bridgman method

Fig. 8: comparison between the experimental true stress-strain curves and those corresponding to the fit of these curves by the Hollomon law. Different fits are represented: fits up to the onset of necking, up to strain equals to 0.3 and 0.4 and up to the break point.

Fig. 9: Experimental and numerical dimensionless load-displacement curves obtained for the AISI 1035 (a), AISI 1065 (b), AISI 1100 (c) and AISI 4135 (d) steels.

Fig. 10: Plastic strain isovalues obtained with the studied steels for an applied load of 200N and with a spherical indenter of radius $\mathrm{R}=0.5 \mathrm{~mm}$ : AISI 1035 (a), AISI 1065 (b), AISI 1100 (c) and AISI 4135 (d) steels.

Fig. 11: Displacement of the center of the ball indenter obtained with Eqs. (7) and (8) and that calculated numerically by F.E.M (tungsten carbide indenter : $\mathrm{E}=600000 \mathrm{MPa}, v=0,28$; indented material : AISI 1035 and 1100 steels).

Fig. 12: Comparison between the numerical F-h curve obtained for a rigid indenter and that obtained by using Eqs (6) and (8) for a tungsten carbide indenter (tungsten carbide indenter : $\mathrm{E}=600000 \mathrm{MPa}, v=0,28$, indented material : AISI 1035 steel).

Fig. 13: Evolution of the radial displacement of the point located at the edge of the contact during unloading indentation. Results are obtained numerically for a maximum applied load equal to $200 \mathrm{~N}$ and for elastic plastic materials similar to the studied steels.

Fig. 14: Dimensionless contact radius, a/R, measured experimentally and calculated by the theoretical models.

Fig. 15: Relationship between the hc/h ratio and the penetration depth, h/R. Comparison between the experimental results and those obtained by theoretical models.

Fig. A.1 : Schematic representation of sinking-in (a) and piling-up (b) of material around spherical indents. 


\begin{tabular}{lllc}
\hline Steels & Initial state & Heat treatment conditions & $\begin{array}{c}\text { Vickers hardness } \\
\mathbf{( 3 0 K g )}\end{array}$ \\
\hline AISI 1035 & Normalized state & Spheroidization $\left(710^{\circ} \mathrm{C}, 10 \mathrm{~h}\right)$ & 156 \\
\hline AISI 1065 & Normalized state & Spheroidization $\left(710^{\circ} \mathrm{C}, 10 \mathrm{~h}\right)$ & 181 \\
\hline AISI 1100 & Spheroidized state & - & 170 \\
\hline AISI 4135 & Normalized state & Spheroidization $\left(710^{\circ} \mathrm{C}, 10 \mathrm{~h}\right)$ & 198 \\
\hline
\end{tabular}


Table 2

\begin{tabular}{lcccc}
\hline & \multicolumn{2}{c}{ Indenter of radius $\mathrm{R}=0.5 \mathrm{~mm}$} & \multicolumn{2}{c}{ Indenter of radius $\mathrm{R}=1.25 \mathrm{~mm}$} \\
\hline & $\mathrm{C}_{\mathrm{m}}\left(\mathrm{mm} / \mathrm{N}^{*} 10^{6}\right)$ & $\mathrm{E}^{*}(\mathrm{~N} / \mathrm{mm})$ & $\mathrm{C}_{\mathrm{m}}\left(\mathrm{mm} / \mathrm{N}^{*} 10^{6}\right)$ & $\mathrm{E}^{*}(\mathrm{~N} / \mathrm{mm})$ \\
\hline $\begin{array}{l}\text { Experimental } \\
\text { results }\end{array}$ & 3.56 & 160374 & 3.96 & 168484 \\
\hline Theoretical values & & 170000 & & 170000 \\
\hline
\end{tabular}




\begin{tabular}{ccccc}
\hline Material & $\begin{array}{c}\text { Yield stress } \\
(\mathbf{M P a})\end{array}$ & $\begin{array}{c}\text { Tensile stress } \\
\mathbf{( M P a )}\end{array}$ & $\begin{array}{c}\text { Elongation at } \\
\text { break } \\
\text { (in \%) }\end{array}$ & $\begin{array}{c}\text { Strain hardening } \\
\text { exponent }\end{array}$ \\
\hline AISI 1035 steel & 300 & 491 & 28.6 & 0.135 \\
\hline AISI 1065 steel & 285 & 641 & 23.4 & 0.2 \\
\hline AISI 1100 steel & 195 & 554 & 30.8 & 0.233 \\
\hline AISI 4135 steel & 472 & 638 & 21.8 & 0.105 \\
\hline
\end{tabular}


Table 1: AISI standard specifications, initial state, heat treatment conditions and Vickers hardness of the studied steels.

Table 2: Experimental values of the load frame compliance and the reduced modulus.

Table 3: Tensile properties of the studied materials. 